\title{
A prophylactic $\alpha$-Gal-based glycovaccine effectively protects against murine acute Chagas disease
}

\author{
Susana Portillo ${ }^{1}$, Brenda G. Zepeda ${ }^{1}$, Eva Iniguez ${ }^{1}$, Janet J. Olivas ${ }^{1}$, Nasim H. Karimi ${ }^{1}$, Otacilio C. Moreira ${ }^{2}$, Alexandre F. Marques ${ }^{1,3}$,
} Katja Michael ${ }^{4}$, Rosa A. Maldonado ${ }^{1}$ and Igor C. Almeida (iD) ${ }^{1}$

Chagas disease $(\mathrm{ChD})$, caused by the hemoflagellate parasite Trypanosoma cruzi, affects six to seven million people in Latin America. Lately, it has become an emerging public health concern in nonendemic regions such as North America and Europe. There is no prophylactic or therapeutic vaccine as yet, and current chemotherapy is rather toxic and has limited efficacy in the chronic phase of the disease. The parasite surface is heavily coated by glycoproteins such as glycosylphosphatidylinositol (GPI)-anchored mucins (tGPI-mucins), which display highly immunogenic terminal nonreducing a-galactopyranosyl (a-Gal)-containing glycotopes that are entirely absent in humans. The immunodominant tGPI-mucin a-Gal glycotope, the trisaccharide Gala1,3Gal $\beta 1,4 \mathrm{GICNAc}(\mathrm{Gala} 3 \mathrm{LN})$, elicits high levels of protective $T$. cruzi-specific anti-a-Gal antibodies in ChD patients in both the acute and chronic phases. Although glycoconjugates are the major parasite glycocalyx antigens, they remain completely unexplored as potential ChD vaccine candidates. Here we investigate the efficacy of the $T$. cruzi immunodominant glycotope Gala3LN, covalently linked to a carrier protein (human serum albumin (HSA)), as a prophylactic vaccine candidate in the acute model of ChD, using the a1,3galactosyltransferase-knockout (a1,3GalT-KO) mouse, which mimics the human immunoresponse to a-Gal glycotopes. Animals vaccinated with Gala3LN-HSA were fully protected against lethal T. cruzi challenge by inducing a strong anti-a-Gal antibodymediated humoral response. Furthermore, Gala3LN-HSA-vaccinated a1,3GalT-KO mice exhibited significant reduction (91.7-99.9\%) in parasite load in all tissues analyzed, cardiac inflammation, myocyte necrosis, and T cell infiltration. This is a proof-of-concept study to demonstrate the efficacy of a prophylactic a-Gal-based glycovaccine for experimental acute Chagas disease.

npj Vaccines (2019)4:13; https://doi.org/10.1038/s41541-019-0107-7

\section{INTRODUCTION}

Chagas disease $(\mathrm{ChD})$, caused by the protozoan parasite Trypanosoma cruzi, is a devastating vector-borne disease affecting six to seven million people worldwide. The disease is endemic in Latin American countries, but owing to globalized migration flows, it has lately become an emerging public health problem to nonendemic regions such as the U.S. and Europe. ${ }^{1}$ About $20-30 \%$ of infected individuals develop cardiomyopathy and/or digestive megasyndromes, leading to disability or death, and significant social and economic burden. ${ }^{2}$ The approved drugs for ChD treatment (i.e., benznidazole and nifurtimox) are very effective in the acute phase, which is rarely diagnosed in the majority of infected individuals. Chemotherapy in the chronic phase, however, is partially effective and may have serious side effects, resulting in premature termination of treatment in $10-20 \%$ of patients. ${ }^{3}$ It is estimated that no more than $1 \%$ of the chronic patients undergo treatment. ${ }^{4}$ There is no prophylactic or therapeutic vaccine for ChD. ${ }^{5,6}$

Over the years, many attempts have been made to develop experimental, preventive, and therapeutic vaccines using attenuated parasites, parasite lysates, or extracts; purified or recombinant protein subunits; and more recently, recombinant
DNA. With few exceptions, however, most of these potential vaccine candidates provide partial to no protection against $T$. cruzi in different mouse models. ${ }^{5,6} \mathrm{~A}$ major bottleneck for the rational development of an effective protein- or peptide-based experimental vaccine to $\mathrm{ChD}$ is the limited proteomic information available on major strains, isolates, and clones representing the six parasite genotypes. ${ }^{7-10}$ This results in a scarcity of information on universal and conserved protein epitopes to be explored as experimental vaccine candidates. More recently, however, a recombinant adenovirus vaccine, using conserved gene sequences from the amastigote surface protein 2 (ASP2) and trans-sialidase (TS) family, has been evaluated as therapeutic vaccine candidate in mice, providing a significant reduction of cardiac pathology and improving disease outcome. ${ }^{11}$ In that study, the protective role of $\mathrm{CD}^{+}{ }^{+} \mathrm{T}$ cells against experimental $T$. cruzi infection corroborated several previous observations (reviewed in ref. ${ }^{12}$ ). Furthermore, a chimeric vaccine containing domains of ASP2 and TS, known as Traspain, also showed the ability to prime effector $\mathrm{CD}^{+} \mathrm{T}$ cells and control parasite dissemination. ${ }^{13}$ Other antigens such as Tc24 (or flagellarcalcium-binding protein) and trypomastigote surface antigen (TSA-1), both as recombinant proteins, also induced memory $\mathrm{CD}^{+}$and $\mathrm{CD}^{+}{ }^{+} \mathrm{T}$ cells, resulting in parasite clearance, decrease

\footnotetext{
${ }^{1}$ Department of Biological Sciences, Border Biomedical Research Center, The University of Texas at El Paso, El Paso, TX, USA; ${ }^{2}$ Laboratório de Biologia Molecular e Doenças Endêmicas, Fundação Instituto Oswaldo Cruz (Fiocruz), Rio de Janeiro, Rio de Janeiro, Brazil; ${ }^{3}$ Departamento de Parasitologia, Instituto de Ciências Biológicas, Universidade

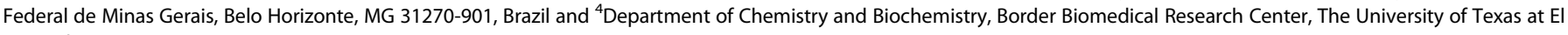
Paso, El Paso, TX, USA

Correspondence: Igor C. Almeida (icalmeida@utep.edu)

These authors contributed equally: Susana Portillo, Brenda G. Zepeda, Eva Iniguez
}

Received: 1 August 2018 Accepted: 30 January 2019

Published online: 22 March 2019 
of cardiac parasite burden, and long-term immunity. ${ }^{14}$ These vaccines and a few others ${ }^{5,6}$ are promising candidates; the conservation of these protein/peptide epitopes, however, among the six genotypes and their multitude of strains and isolates remains unproven. This is a recurrent issue in the development of effective peptide-/protein-based vaccines for ChD.

The T. cruzi glycocalyx is composed of abundant, complex, highly variable, and immunogenic glycosylphosphatidylinositol (GPI)-anchored glycoproteins and glycolipids, such as mucins, mucin-associated surface proteins (MASPs), TS/gp85 glycoproteins, and glycoinositolphospholipids. ${ }^{10}$ Different expression levels of these antigens are observed throughout the life-cycle stages of the parasite. For instance, in the infective host cellderived trypomastigote (tissue culture-derived trypomastigote (TCT)) stage, the predominant glycoproteins belong to the mucin family, with members containing up to $60 \%$ of their molecular mass composed of O-glycans. ${ }^{10,15,16}$ Trypomastigotederived GPI-anchored mucins (tGPI-mucins) contain the linear immunodominant glycotope Gala1,3Galß1,4GlcNAc (Gala3LN)

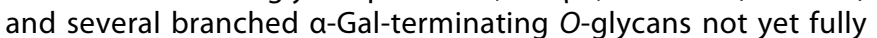
characterized. ${ }^{15}$ These a-Gal glycotopes induce high levels of $T$. cruzi-specific anti-a-Gal antibodies in ChD patients (Ch anti-aGal Abs). ${ }^{15,17-22}$ The $\mathrm{Ch}$ anti-a-Gal Abs are protective, thus effectively controlling the parasitemia in both the acute and chronic phases of $\mathrm{ChD}$ and are universally and abundantly found in patients from endemic and nonendemic countries. ${ }^{15,19-24}$ Moreover, the $\mathrm{Ch}$ anti-a-Gal Abs have both specificity and biological activity considerably distinct from the so-called natural (or normal human serum (NHS)) anti-a-Gal Abs. The latter is elicited mainly against Gram-negative enterobacteria of the human gut flora, ${ }^{25,26}$ which express a wide variety of terminal nonreducing a-Gal-linked glycans, predominantly Gala1,2-, Gala1,4-, and Gala1,6-R, where R is the residual side chain or glycan on the lipopolysaccharide core oligosaccharides or O-antigens. ${ }^{27}$ Thus far, the immunodominant glycotope Gala3LN on tGPI-mucins, which is a major target for the $\mathrm{Ch}$ anti-a-Gal Abs, has not yet been reported in any enterobacteria. ${ }^{27}$ Therefore, in comparison with $\mathrm{Ch}$ anti-a-Gal Abs, the NHS anti-a-Gal Abs have a much weaker binding affinity to the linear Gala3LN ${ }^{28,29}$ glycotope and branched aGal-terminating $\mathrm{O}$-glycans on tGPI-mucins. ${ }^{15}$ Consequently, the NHS anti-a-Gal Abs have substantially lower trypanolytic activity than Ch anti-a-Gal Abs on both TCTs and insect-derived metacyclic trypomastigotes. ${ }^{15,19}$

Since terminal, nonreducing, and linear a-Gal glycotopes (e.g., Gala1,3Gal, Gala1,3Galß1,4GlcNAc) are absent in human tissues, ${ }^{30}$ we hypothesized that an effective vaccine against $T$. cruzi could be achieved using these highly immunogenic B cell glycotopes, in combination or not with $\mathrm{CD}^{+} \mathrm{T}$ cell epitopes. Actually, it has been recently suggested that a-Gal glycotope(s) could be employed in a pan-vaccine against major infectious diseases, such as malaria, ChD, leishmaniasis, African trypanosomiasis, and tuberculosis. ${ }^{31}$ In support of this idea, a-Gal-based vaccines have been shown to induce considerable protection against different species of Plasmodium $^{32}$ and Leishmania. ${ }^{33,34}$ Thus far, however, no a-Galbased vaccine has been tested in the context of experimental ChD.

Here we evaluated the trisaccharide Gala1,3Galß1,4GlcNAc (Gala3LN), also known as the Galili or a-Gal epitope or glycotope, ${ }^{26}$ coupled to the carrier protein human serum albumin (Gala3LN-HSA), in the presence or not of adjuvant liposomalmonophosphoryl lipid A (LMPLA), as a potential experimental vaccine to acute $\mathrm{ChD}$. To this end, we employed the a1,3galactosyltransferase-knockout ( $\mathrm{a} 1,3 \mathrm{GalT}-\mathrm{KO})$ mouse model, ${ }^{35,36}$ which closely mimics human humoral responses against $a-G a l$ glycotopes.

\section{RESULTS}

a1,3GalT-KO mice are naturally more resistant to $T$. cruzi infection Mice and all other mammals, except for humans and Old-World nonhuman primates, express the Galili or a-Gal glycotope on their cells and are therefore tolerant to this antigen. ${ }^{2,30,37}$ The a-Gal glycotope is the immunodominant epitope found in infective $T$. cruzi trypomastigote forms, ${ }^{15,19}$ responsible for eliciting high levels of protective anti-a-Gal Abs in both acute and chronic ChD. ${ }^{17-20}$ These Abs are capable of controlling the parasitemia in both disease stages in a complement-dependent and -independent manner. ${ }^{15,19,20,22,38}$ To substantiate the role of anti-a-Gal Abs in protection against the parasite in a well-defined experimental model, we employed the a1,3GalT-KO mouse model that, akin to humans, do not express terminal a-Gal glycotopes on their cells due to the disruption of the UDP-galactose: $\beta$-galactoside- $a-1,3-$ galactosyltransferase (a1,3GalT) gene. ${ }^{36,39}$ First, we compared the response to $T$. cruzi infection of wild-type (a1,3GalT-WT) and a1,3GalT-KO mice, both in the C57BL/6 background. We infected (intraperitoneally (i.p.)) both groups of mice $(n=5-10$, each) with $1 \times 10^{3}$ TCTs of $T$. cruzi ( $\mathrm{Y}$ strain). Mice were assessed for parasitemia, survival, and anti-a-Gal Ab titers. As observed in Fig. $1 \mathrm{a}$, the acute parasitemia was much lower in a1,3GalT-KO mice than in the control WT group. The a1,3GalT-KO group also showed a much higher survival rate $(\sim 70 \%)$ in comparison to the WT group (Fig. 1b). In the latter, all mice died within 105 days postinfection (dpi). Next, we investigated whether the a1,3GalT-KO mice were able to produce specific anti-a-Gal Abs. For this, Gala3LN-BSA was used as antigen and chemiluminescent enzyme-linked immunosorbent assay (CL-ELISA) ${ }^{29}$ was performed as described in Methods. As expected, the a1,3GalT-KO group produced significantly higher levels of anti-a-Gal Abs during the course of infection when compared with the a1,3GalT-WT group (Fig. 1c). As expected, the a1,3GalT-WT group showed a much lower titer of anti-a-Gal Abs in total serum than the a1,3GalT-KO group. To assess the specificity of anti-a-Gal Abs produced by both groups, we treated the immobilized Gala3LN-BSA antigen with green coffee bean a-galactosidase to remove terminal a-Gal residues and observed no reactivity, suggesting that the majority of Abs were produced against the terminal nonreducing a-Gal glycotope. We then analyzed proinflammatory (interferon (IFN)- $\psi$, tumor necrosis factor (TNF)- $a$, and interleukin (IL)-2) and regulatory (IL-4 and IL-10) cytokines in the serum of a1,3GalT-KO and -WT animals through the course of $T$. cruzi infection. a1,3GalT-WT mice showed high levels of IFN- $\gamma$, TNF- $a$, and IL-10 in the early stage of infection (day 7). However, these cytokines decreased significantly throughout the course of infection, reaching levels comparable to the naive $(\mathrm{N})$ control mice at day 28 . The levels of IL-2 and IL-4, on the other hand, slightly decreased or remained almost unaltered between 7 and $28 \mathrm{dpi}$ in the a1,3GalT-WT mice (Fig. 1d). Conversely, a1,3GalT-KO mice showed increasingly higher levels of all cytokines tested from 7 to $28 \mathrm{dpi}$.

Anti-a-Gal Abs from a1,3GalT-KO mice are protective as human anti-a-Gal Abs

When we expose TCTs to sera of $28 \mathrm{dpi}$ from a1,3GalT-KO and -WT mice, high trypanolytic activity is observed, killing an average of $78 \%$ of TCTs after $1 \mathrm{~h}$ incubation at $37^{\circ} \mathrm{C}$ (Fig. 1e). Similarly, $T$. cruzi-specific anti-a-Gal Abs purified from acute and chronic ChD patients have cytotoxic (trypanolytic) effects on both metacyclic trypomastigotes and TCT forms of the parasite in vitro. ${ }^{19,20,22}$ Next, we purified anti-a-Gal Abs produced by a1,3GalT-KO mice to investigate whether these Abs are also trypanolytic. First, the lytic property of the purified anti-a-Gal Abs was evaluated by incubation with TCTs at three different concentrations (1, 10, and $100 \mu \mathrm{g} / \mathrm{mL}$ ), and motile parasites were counted. Unbound immunoglobulin G (IgG) (non-anti-a-Gal Abs) from the Gala3LNSynsorb column was used as negative control (Fig. 1f). Purified 

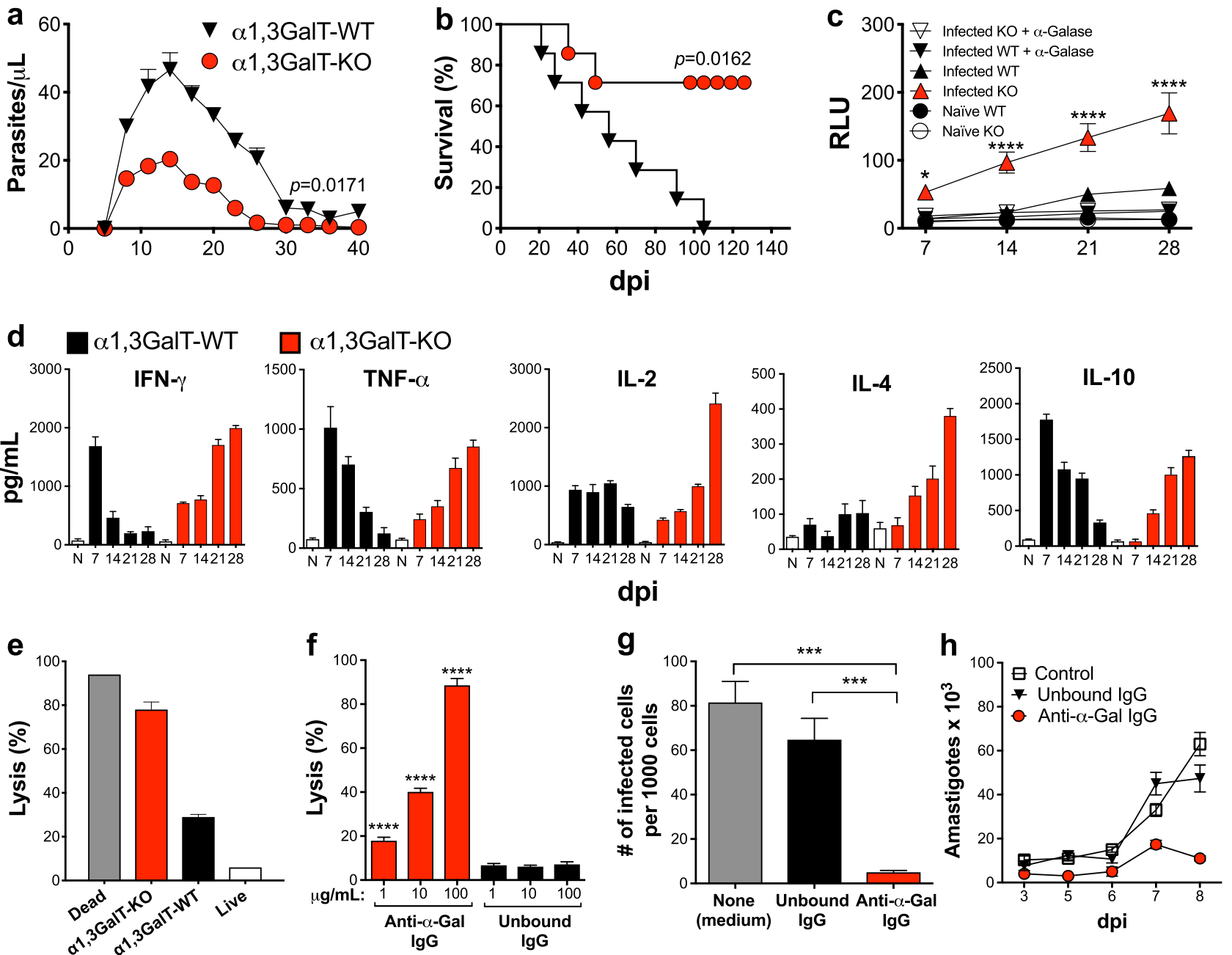

Fig. $1 \alpha 1,3 \mathrm{GalT-WT}$ and $\alpha 1,3 \mathrm{GalT-KO}$ mice exhibit different immune responses to T. cruzi infection. a Parasitemia in $\alpha 1,3 \mathrm{GalT}-\mathrm{WT}$ and $\alpha 1,3 \mathrm{GalT}$ KO mice infected (intraperitoneally (i.p.)) with $1 \times 10^{3}$ tissue culture-derived trypomastigotes (TCTs) (Y strain). b Kaplan-Meier survival rate curve of animals infected with $1 \times 10^{4} \mathrm{TCTs}$ (Y strain). c Anti- $\alpha$-Gal Ab levels as measured by chemiluminescent enzyme-linked immunosorbent assay using Gal $\alpha 3 \mathrm{LN}-\mathrm{BSA}$ as antigen. RLU relative luminescence units. Infected C57BL/6 $\alpha 1,3 \mathrm{GalT}-\mathrm{WT}$ mice were compared to knockout (KO) mice by two-way analysis of variance (ANOVA) with Tukey's multiple comparison test. ${ }^{*} p<0.05 ;{ }^{* * * *} p<0.0001$. d Serum cytokine profile of $\alpha 1,3 \mathrm{GaIT}-W T$ and $\alpha 1,3 \mathrm{GalT}-\mathrm{KO}$ mice infected (i.p.) with $1 \times 10^{3} \mathrm{TCTs}$ and followed up for 28 days. N naive. Lysis of TCTs $\left(1 \times 10^{7} / \mathrm{mL}\right)$ by serum e or purified anti- $\alpha$-Gal Abs f from $\alpha 1,3 \mathrm{GalT}$-WT and $\alpha 1,3 \mathrm{GalT}-\mathrm{KO}$ mice infected (i.p.) with $1 \times 10^{3}$ TCTs. Unbound immunoglobulin G (IgG), nonanti- $\alpha$-Gal IgG antibodies (Abs) (flow through) from Synsorb 115 immunoaffinity chromatography; anti- $\alpha$-Gal lgG, anti- $\alpha$-Gal Abs eluted from Synsorb 115. Inhibition of parasite host cell invasion $\mathbf{g}$ and intracellular amastigote proliferation $\mathbf{h}$. LLC-MK2 cells were infected with $\mathrm{Y}$ strain TCTs (multiplicity of infection $=10$ ), for $2 \mathrm{~h}$ at $37^{\circ} \mathrm{C}$, in the presence or not of $100 \mu \mathrm{g} /$ well of murine non-anti- $\alpha-\mathrm{Gal}$ lgG Abs (Unbound lgG from Synsorb 115) or purified murine anti- $\alpha-$ Gal IgG Abs or control (None, medium alone). Number of infected cells per 1000 cells was evaluated after staining with 4,6-diamidino-2-phenylindole. $\mathbf{a}, \mathbf{b}, \mathbf{f}, \mathbf{g}$ One-way ANOVA with Dunn's multiple comparisons test. ${ }^{* * *} p<0.001 ; * * * * p<0.0001$. The $p$ values in $\mathbf{a}, \mathbf{b}$ pertain to the mean values of the $\alpha 1,3 \mathrm{GalT}$-KO group in comparison with the $\alpha 1,3 \mathrm{GalT}$-WT throughout the course of the experiment. Error bars indicate S.E.M

anti-a-Gal Abs agglutinated and killed $\sim 90 \%$ of the parasites (in a concentration-dependent manner) in the absence of complement, which is in agreement with the previous observations of anti-a-Gal Abs purified from acute or chronic ChD patients. ${ }^{15,20,22}$ To evaluate the ability of purified murine anti-a-Gal IgG Abs to prevent host cell infection and intracellular parasite proliferation, cells were infected and $100 \mu \mathrm{g} / \mathrm{mL}$ of murine anti-a-Gal Abs was added simultaneously. We observed that purified anti-a-Gal IgG Abs, but not unbound IgG Abs or medium alone, were able to significantly block infection (Fig. 1g). The number of intracellular amastigotes per cell (parasite proliferation), evaluated at 3-8 dpi, was significantly reduced, most likely due to the lower infection rate in the presence of purified murine anti-a-Gal lgG Abs but not of unbound IgG Abs or medium alone (negative control) (Fig. 1h). Taken together, these results clearly demonstrated that anti-a-Gal Abs elicited by $T$. cruzi-infected a1,3GalT-KO mice have cytotoxic and protective properties against the parasite similar to the anti-aGal Abs purified from ChD patients. ${ }^{19,22}$

The a-Gal glycotope protects a1,3GalT-KO mice against $T$. cruzi infection

We evaluated whether immunization with a neoglycoprotein (NGP) containing the a-Gal glycotope could elicit protection against $T$. cruzi challenge. Groups of six female mice each were immunized with an NGP Gala3LN-HSA ( $20 \mu \mathrm{g}$ per dose per mouse) alone or in combination with an adjuvant, LMPLA, Gala3LN-HS A+/-LMPLA. Control groups consisted of animals injected with the carrier protein and adjuvant combination (HSA+LMPLA), naive (nonimmunized, noninfected), or challenged (nonimmunized, infected) animals. The last two doses for all groups did not include LMPLA. As shown in Fig. 2a, serum was collected 3 days 
a

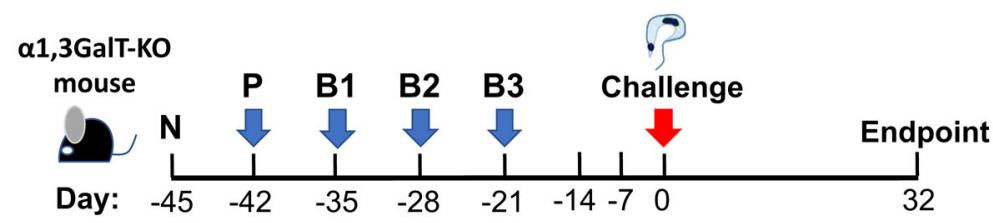

b

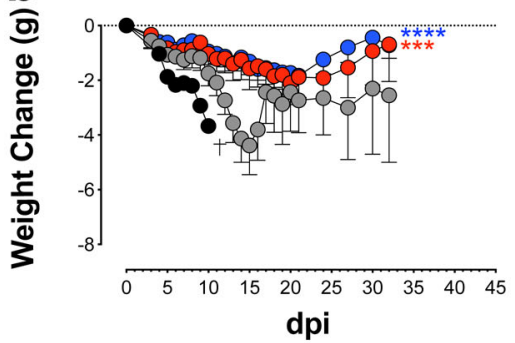

C

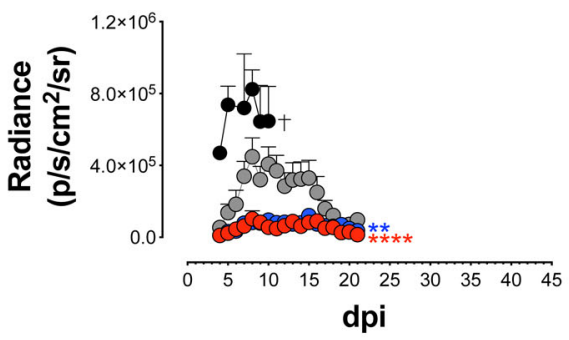

e

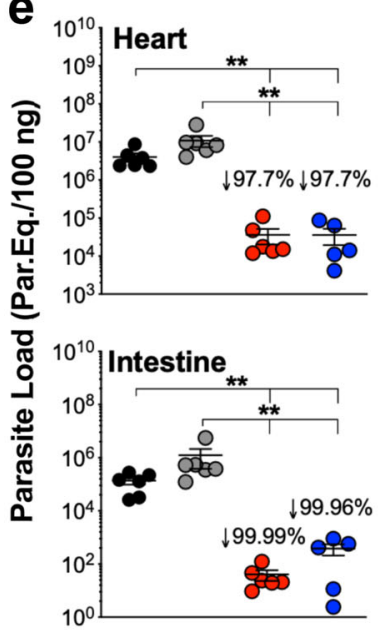

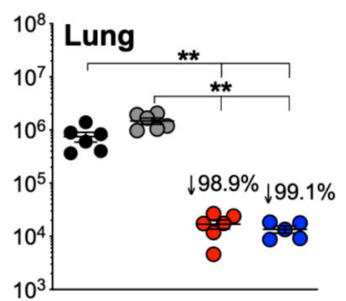

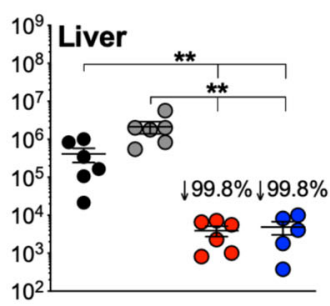

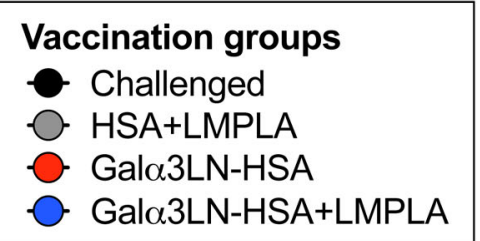

d

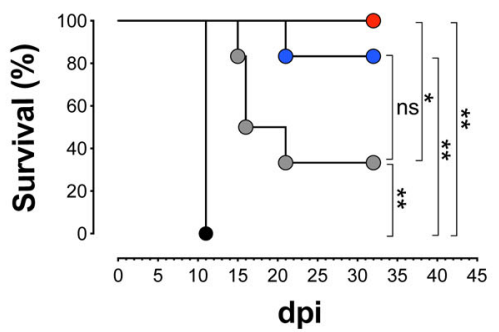

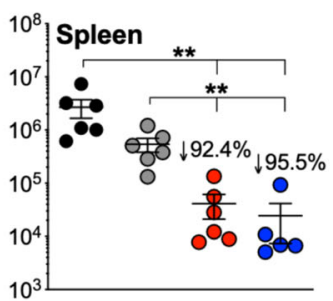

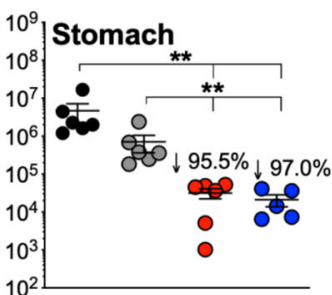

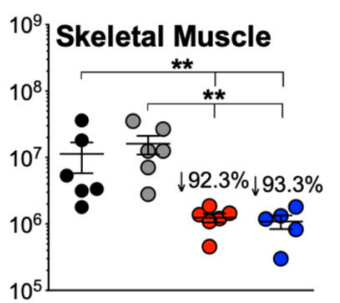

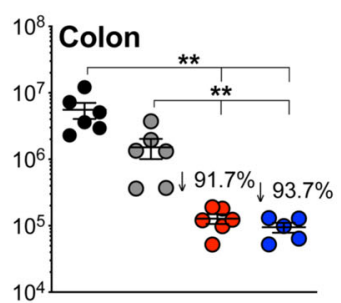

Organ

Fig. 2 Vaccination with Gal $\alpha 3 \mathrm{LN}-\mathrm{HSA}$ or Gal $\alpha 3 \mathrm{LN}-\mathrm{HSA}+\mathrm{LMPLA}$ protects $\alpha 1,3 \mathrm{GalT}-\mathrm{KO}$ mice against $T$. cruzi infection. a Experimental design scheme. $\mathrm{N}$ naive (before prime); $\mathrm{P}$ prime; B1-B3, boosts $1-3$. Three weeks after $\mathrm{B} 3$, immunized $\alpha 1,3 \mathrm{GalT}$-KO mice were challenged (intraperitoneally) with $1 \times 10^{5} \mathrm{~T}$. cruzi CL Brener-luc tissue culture-derived trypomastigotes. Experimental endpoint was 32 days postinfection. b Weight change in grams (g) assessed in immunized (Gal $\alpha 3$ LN-HSA+/-LMPLA) and control (HSA+LMPLA) $\alpha 1,3 G a l T-K O$ mice daily after parasite challenge. One-way analysis of variance (ANOVA) with Dunn's multiple comparisons test was performed comparing the immunized (Gal $\alpha 3 \mathrm{LN}-\mathrm{HSA}+/$-LMPLA) groups with the control group (HSA+LMPLA); $p$ values indicate the significance for the whole group. ${ }^{*} p<0.05 ;{ }^{* *} p<0.01 ;{ }^{* * *} p<0.001 ;{ }^{* * *} p<0.0001$. Death of all animals $(n=3)$ in the challenged-only group is indicated $(\dagger)$. Error bars indicate S.E.M. c In vivo bioluminescence imaging of $\alpha 1,3 \mathrm{GalT-KO}$ mice was performed to quantify parasite burden in the whole body following parasite challenge. Images were obtained daily and radiance $\left(\mathrm{p} / \mathrm{s} / \mathrm{cm}^{2} / \mathrm{sr}\right)$ was plotted. One-way ANOVA with Dunn's multiple comparisons test was performed comparing the immunized (Gal $\alpha 3 \mathrm{LN}-\mathrm{HSA}+/-\mathrm{LMPLA}$ ) groups with the control group (HSA+LMPLA); $p$ values indicate the significance for the whole group. ${ }^{* *} p<0.01{ }^{* * * *} p<0.0001$. Error bars indicate S.E.M. Death of all animals $(n=3)$ in the challengedonly group is indicated $(\dagger)$. d Kaplan-Meier survival rate was assessed and recorded in each animal group ( $n=6$ per group in all groups, except for group "Challenged") after parasite challenge. Log-rank (Mantel-Cox) test was performed to compare the immunized groups (Galo3LN-HSA+/-LMPLA) with the control groups (Challenged-only and HSA-LMPLA). ${ }^{*} p<0.05$; ${ }^{* *} p<0.01$. e Determination of parasite load by quantitative real-time PCR in the heart, lung, spleen, skeletal muscle, intestine, liver, stomach, and colon, using satellite DNA of $T$. cruzi. Parasite load is expressed as parasite equivalents per $100 \mathrm{ng}$ of tissue. Reduction of parasite load was calculated by dividing the mean of experimental vaccines by the HSA+LMPLA control group. Error bars indicate S.E.M. of triplicate determinations. Student's $t$ test with Mann-Whitney was performed to compare the immunized groups (Gal $\alpha 3$ LN-HSA+/-LMPLA) with the control groups (Challenged-only and HSA-LMPLA). ${ }^{* *} p<0.01$. The $p$ values in $\mathbf{b}$, $\mathbf{c}$ pertain to the mean values of each immunized group in comparison with the HSA+LMPLA control group throughout the course of the experiment

before prime immunization (naive, $\mathrm{N}$ ) to obtain baseline levels. Then animal groups received a prime $(P)$ and three boost immunizations (B1-B3), i.p., at 7-day intervals, followed by an i.p. T. cruzi challenge with $1 \times 10^{5}$ TCTs (CL Brener clone) expressing red-shifted luciferase $\left(\mathrm{CL}\right.$ Brener-luc), ${ }^{40} 3$ weeks after the last immunization (B3). The experimental endpoint was $32 \mathrm{dpi}$, when all mice were humanely euthanized. Serum was obtained 3 days after each immunization and throughout the remainder of the experiment. Upon infection, mice were observed for abnormal behavior and toxicity signs, and their weights were recorded daily. Any weight change was normalized to the animal's initial weight (Fig. 2b). We observed that both groups, Gala3LN-HSA $(p<0.001)$ and Gala3LN-HSA+LMPLA $(p<0.0001)$, lost less weight when compared to the control HSA+LMPLA group and started 

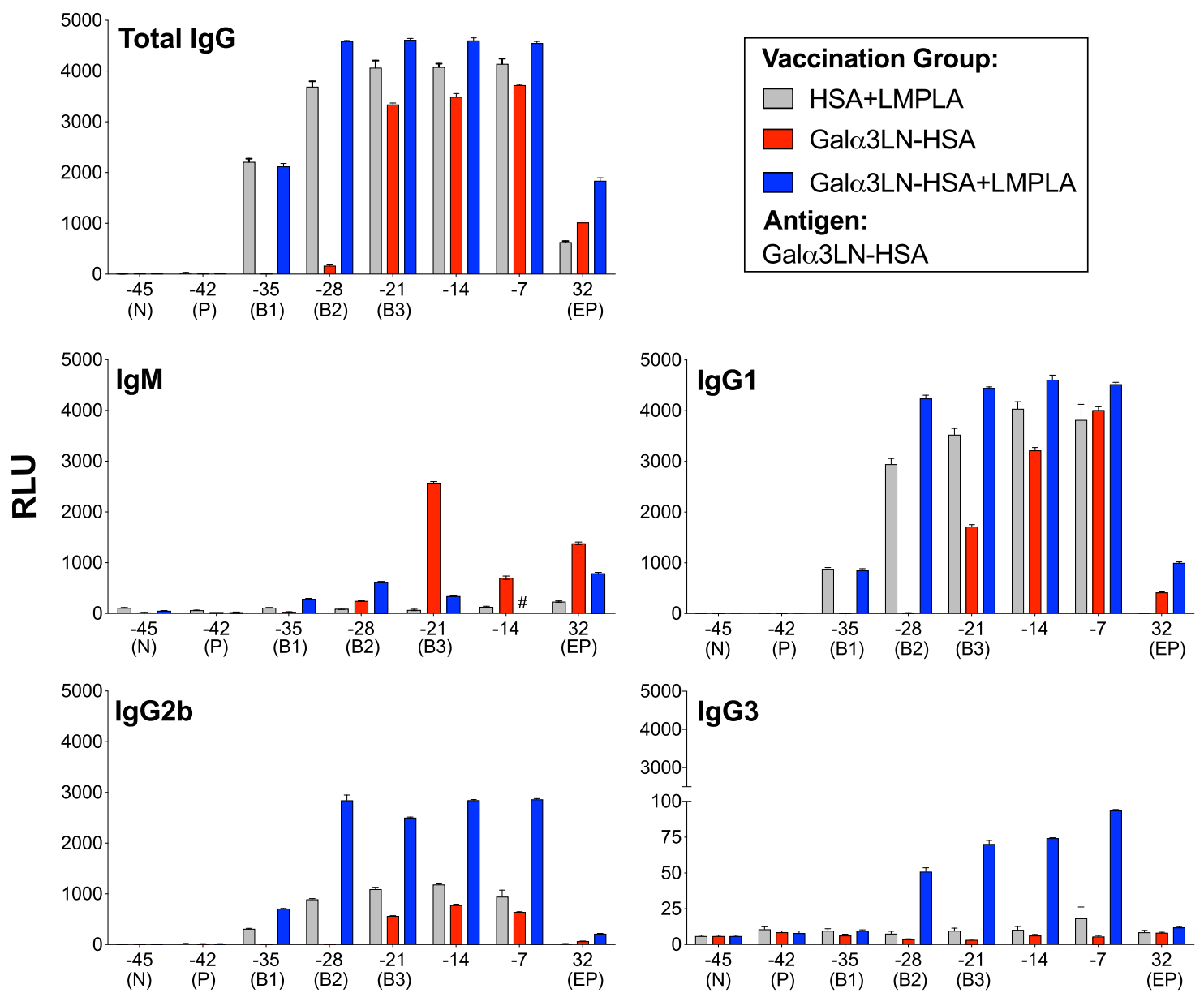

Day

Fig. 3 Kinetics of humoral immune response elicited by Gal 33 LN-HSA, Gal $\alpha 3$ LN-HSA+LMPLA, and HSA+LMPLA. Chemiluminescent enzymelinked immunosorbent assay (CL-ELISA) reactivity of mouse sera from $\alpha 1,3 \mathrm{GalT}-\mathrm{KO}$ mice injected with Gal $\alpha 3 \mathrm{LN}-\mathrm{HSA}$, Gal $\alpha 3 \mathrm{LN}-\mathrm{HSA}+\mathrm{LMPLA}$, or HSA+LMPLA using Gal $\alpha 3$ LN-HSA as immobilized antigen. For immunoglobulin M (IgM) measurement, prior to the CL-ELISA we depleted lgG antibodies by preincubating each serum sample with a $15-\mu \mathrm{L}$ bead suspension mixture of protein A-Sepharose $4 \mathrm{~B}$ and protein $\mathrm{G}-\mathrm{Sepharose}$, both fast flow $(A: G, 1: 1, v / v)$, and recombinant human serum albumin (HSA; $1 \mathrm{mg} / \mathrm{mL})$, for $1 \mathrm{~h}$ at $37^{\circ} \mathrm{C}$ on rotatory shaker. Error bars indicate S.E.M. of triplicate determinations. Sample no longer available is indicated (\#). RLU relative luminescence units

regaining weight few weeks postinfection. In contrast, animals in the HSA+LMPLA group lost considerable weight in the first $15 \mathrm{dpi}$, regaining some weight until the experimental endpoint.

The parasite burden in the three animal groups infected with TCTs of $\mathrm{CL}$ Brener-luc strain was then evaluated using an in vivo bioimager. To this end, mice were injected (i.p.) D-luciferin in sterile phosphate-buffered saline (PBS) and were anesthetized and imaged 10 min after substrate injection. Images of anesthetized mice were captured in automatic exposure and bioluminescence obtained was expressed in radiance (photons per second per square centimeter squared per steradian, $\mathrm{p} / \mathrm{s} / \mathrm{cm}^{2} / \mathrm{sr}$ ) per animal (Fig. 2c). Upon challenge, the Gala3LN-HSA $(p<0.0001)$ and Gala3LN-HSA+LMPLA $(p<0.01)$ groups showed a total parasite burden significantly lower than the HSA+LMPLA control group. Moreover, both Gala3LN-HSA and Gala3LN-HSA+LMPLA exhibited a $100 \%$ and an $83 \%$ survival at endpoint, respectively, when compared to a $33 \%$ survival in the HSA+LMPLA control group (Fig. 2d).

To investigate whether the a-Gal glycotope-based vaccine could also reduce parasite burden, we performed quantitative real-time PCR (qPCR) analysis in the homogenized heart, lung, spleen, skeletal muscle, intestine, liver, stomach, and colon tissues (Fig. 2e). Animals vaccinated with Gala3LN-HSA+/-LMPLA showed a substantial decrease (91.7-99.9\%) in parasite burden in all aforementioned tissues when compared to the HSA+LMPLA control group. Heart and skeletal muscle tissues of animals in the HSA+LMPLA control group showed a much higher parasite load (average of $\sim 10^{7}$ parasite equivalents/100 ng tissue) than all other infected tissues (average of $\sim 10^{6}$ parasite equivalents/100 ng tissue) in the same group. Moreover, the reduction in parasite load in all tissues was also highly significant when comparing both the immunized groups with the challenged only group. Taken together, our results indicated that animals vaccinated with Gala3LN-HSA, with or without adjuvant, have significantly reduced parasitic burden in all tissues analyzed. Taken together, our data clearly demonstrate that immunization of a1,3GalT-KO mice with an NGP containing the a-Gal glycotope, in the presence or not of an adjuvant, can significantly protect mice against lethal parasite challenge.

Kinetics and isotype profile of humoral response in a1,3GalT-KO mice following Gala3LN-HSA or Gala3LN-HSA+LMPLA vaccination To assess the development of a humoral immune response, sera were collected from the vaccinated and control groups 3 days after each timepoint (Fig. 2a), and the kinetics of specific Ab isotypes (lgG, $\lg M, \lg G 1, \lg G 2 b, \lg G 3, \lg A$, and $\lg E$ ) were evaluated (Fig. 3 and Supplementary Figure 1). As anticipated, an early (B1 and B2) and higher total lgG response was observed in the animals vaccinated with Gala3LN-HSA plus adjuvant 

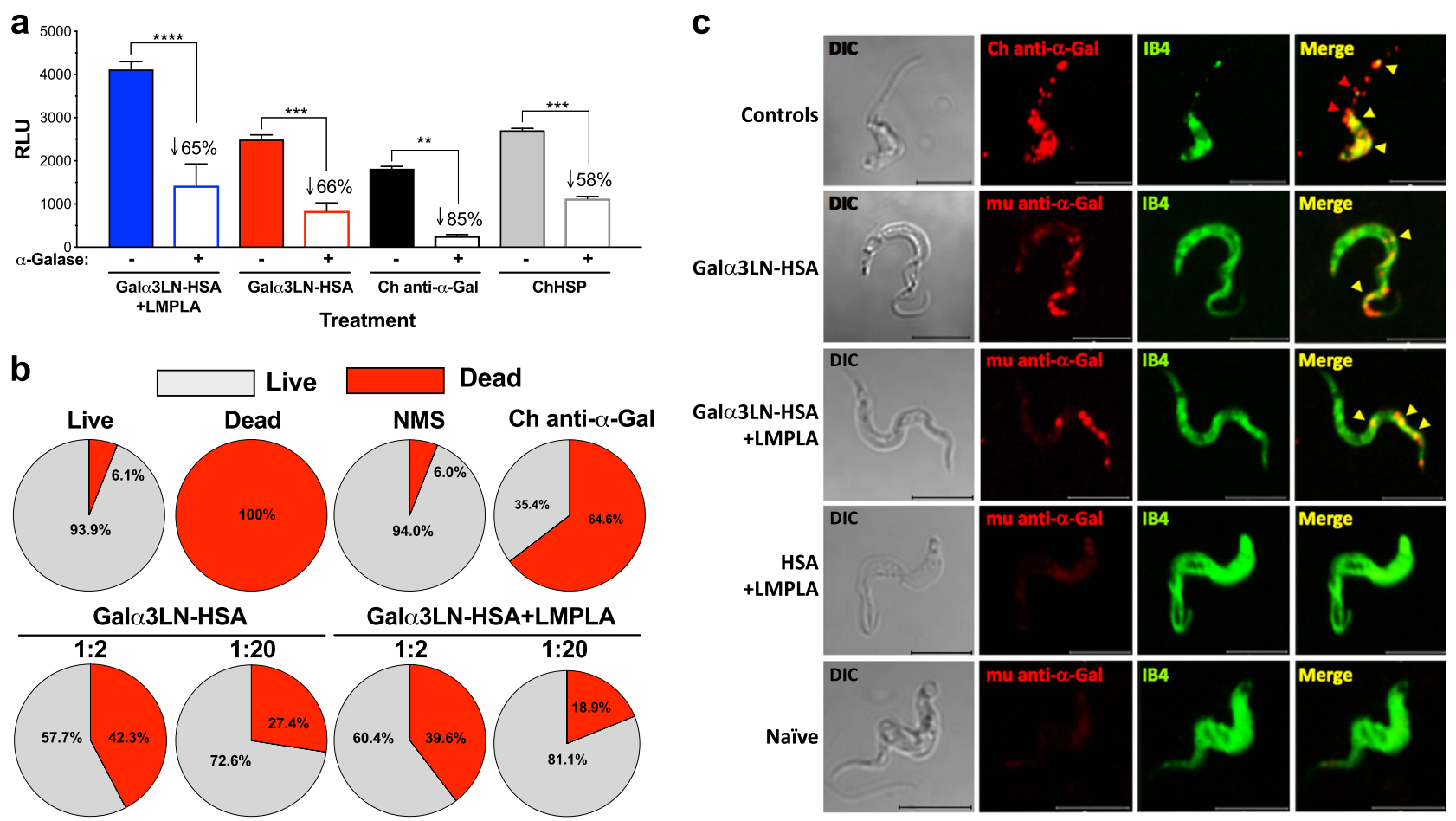

Fig. 4 Anti-Gal $\alpha 3$ LN-HSA Abs are $\alpha$-Gal-specific, have lytic activity, and recognize parasite surface glycotopes. a Chemiluminescent enzymelinked immunosorbent assay reactivity of sera from $\alpha 1,3 \mathrm{GalT}-\mathrm{KO}$ mice vaccinated with Gal $\alpha 3 \mathrm{LN}-\mathrm{HSA}+/-\mathrm{LMPLA}$ before and after green coffee bean $\alpha$-galactosidase ( $\alpha$-Galase) treatment of the immobilized Gal $\alpha$ LNN-HSA antigen. Purified human Chagas (Ch) anti- $\alpha$-Gal immunoglobulin $\mathrm{G}(\mathrm{IgG})$ antibodies (Abs) and human serum pool from chronic Ch disease patients (ChHSP) were used as controls. RLU relative luminescence units. One-way ANOVA with Sidak's multiple comparison test was performed comparing groups before $(-)$ and after $(+) \alpha-g a l a c t o s i d a s e ~(\alpha-$ Galase) treatment; $p$ values indicate the significance of group before and after treatment. ${ }^{* *} p<0.01 ;{ }^{* * *} p<0.001 ;{ }^{* * *} p<0.0001$. $\mathbf{b}$ Percentage of lysis of tissue culture-derived trypomastigotes (TCTs) incubated with sera from $\alpha 1,3 \mathrm{GalT}$-KO mice vaccinated with Gal $\alpha 3 \mathrm{LN}-\mathrm{HSA}+/-\mathrm{LMPLA}$. c Confocal microscopy using murine (mu) anti- $\alpha$-Gal IgG Abs purified from mice vaccinated with Gal $\alpha 3 \mathrm{LN}-\mathrm{HSA}+/-\mathrm{LMPLA}$. Bandeiraea simplicifolia Isolectin IB4 was used to label all terminal $\alpha$-Gal residues on TCT surface. Human Ch anti- $\alpha$-Gal lgG Abs were used as positive control. Bar $5 \mu \mathrm{m}$

(Gala3LN-HSA+LMPLA) when compared with mice immunized with Gala3LN-HSA alone (Fig. 3). In contrast, a lower lgM anti-a-Gal response was observed mainly in the Gala3LN-HSA group, following IgG depletion using protein A-/G-Sepharose. Furthermore, IgG1 was the main IgG isotype, followed by substantial levels of IgG2b elicited in both the a-Gal-vaccinated groups and HSA+LMPLA control (Fig. 3). Low levels of IgG3 were detected only in the Gala3LN-HSA+LMPLA group. Following parasite challenge, a-Gal-vaccinated mice continued to exhibit higher amounts of $\lg G 1$ and $\lg G 2 \mathrm{~b}$ Abs when compared with the baseline $(\mathrm{N}$, day -45$)$ levels. However, these isotypes were considerably reduced at the endpoint. For example, for total lgG, a reduction to $27 \%$ and $40 \%$ of the total maximum reactivity was observed for the Gala3LN-HSA and Gala3LN-HSA+LMPLA groups at day -7 , respectively (Fig. 3, total lgG). However, this reduction cannot be directly correlated to $\mathrm{Ab}$ functionality (i.e., lytic activity) in vivo or in vitro. We estimated the concentration of anti-a-Gal Abs at day $32 \mathrm{dpi}$ to be 83 and $214 \mu \mathrm{g} / \mathrm{mL}$ for the Gala3LN-HSA and Gala3LNHSA+LMPLA groups, respectively. Although reduced, these Ab concentrations are still high and sufficient to effectively kill the parasites (see section below).

$\lg A$ and $\lg E$ responses, on the other hand, were virtually nonexistent following vaccination with Gala3LN-HSA+/-LMPLA (Supplementary Figure 1). We also observed a very strong response to Gala3LN-HSA of total $\lg G$, $\lg G 1$, and $\lg G 2 \mathrm{~b}$ in the control group injected with HSA+LMPLA. This response was significantly reduced or absent at the endpoint as well (Fig. 3). We hypothesized that this strong background response could be due to Abs against HSA. Aiming to address this background reactivity, we used different proteins as immobilized antigens in the CL-
ELISA to measure the levels of non-anti-a-Gal Abs elicited in the Gala3LN-HSA-immunized group during different timepoints (Supplementary Figure 2). We observed an increasing reactivity to HSA following boosts 2 and 3 ( $6 \%$ and $15 \%$ of the total reactivity), reaching a plateau at day -14 (35\%). Furthermore, we could not detect any cross-reactivity to other proteins (i.e., bovine serum albumin (BSA) and casein), used as immobilized antigen (Supplementary Figure 2). In summary, Gala3LN-HSA, Gala3LNHSA+LMPLA, and HSA+LMPLA induced a strong humoral response with the prevalence of $\lg G 1$ and $\lg G 2 b$ isotypes.

Antibodies elicited by a-Gal-based vaccine recognize terminal aGal residues, have trypanolytic activity, and bind to specific a-Galcontaining domains on the parasite surface

To determine the specificity of the Abs produced against Gala3LNHSA+/-LMPLA, microplate-immobilized Gala3LN-HSA was treated with a-galactosidase to remove terminal a-Gal residues, and the serum reactivity from mice immunized with Gala3LN-HSA or Gala3LN-HSA+LMPLA, was determined by CL-ELISA, ${ }^{33}$ as detailed in Methods (Fig. 4a). A significant decrease in the reactivity of sera from both Gala3LN-HSA ( $p<0.001,66 \%$ reduction) and Gala3LNHSA+LMPLA ( $p<0.0001,65 \%$ reduction) group was observed. The remaining reactivity was confirmed to be against HSA (Supplementary Figure 2). As positive controls, purified anti-a-Gal Abs (Ch anti-a-Gal Abs) and a pool of sera (ChHSP), both from chronic ChD patients, were used. Significant decrease in Ab reactivity to the agalactosidase-treated antigen was also observed with $\mathrm{Ch}$ anti-aGal Abs (85\%) and ChHSP (58\%) (Fig. 4a). 
Gala3LN-HSA Gala3LN-HSA+LMPLA $\bigcirc$ Naïve
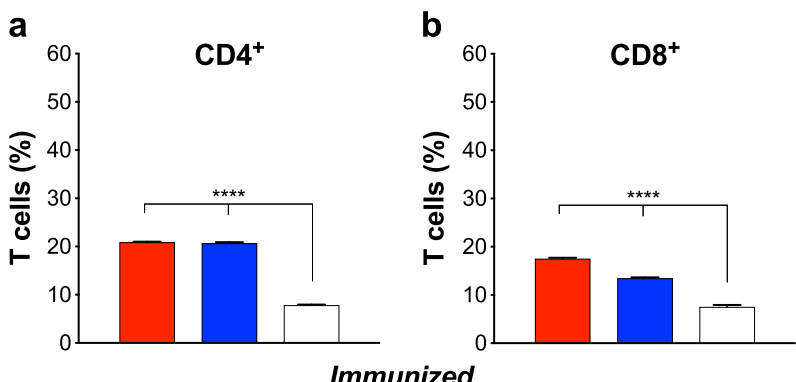

C

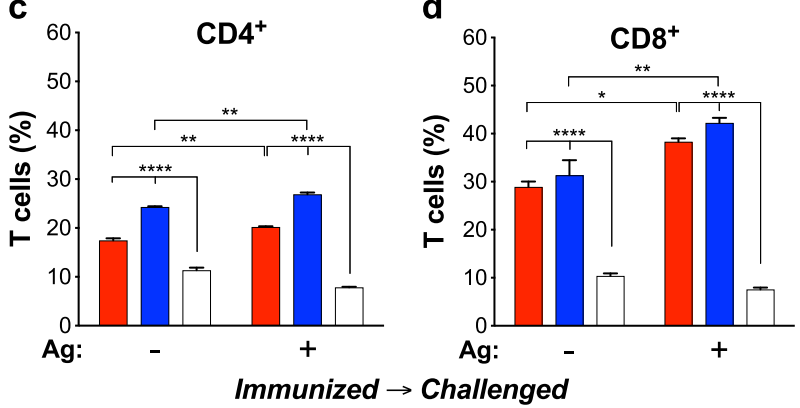

e

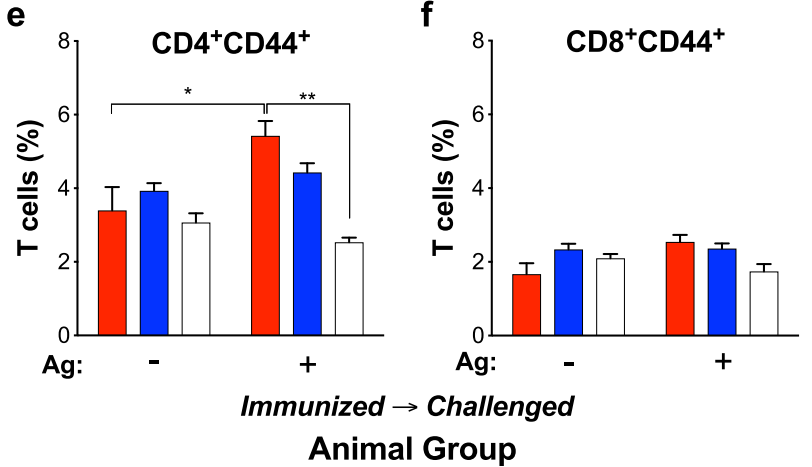

Fig. 5 Vaccination with Gal $\alpha 3 \mathrm{LN}-\mathrm{HSA}+/-\mathrm{LMPLA}$ induce $\mathrm{T}$ cell activation. Splenocytes were collected from mice immunized with Gal $\alpha 3 \mathrm{LN}-\mathrm{HSA}$ or Gal $\alpha 3 \mathrm{LN}-\mathrm{HSA}+\mathrm{LMPLA}$ and immunized-challenged mice, followed by ex vivo stimulation with $20 \mu \mathrm{g} / \mathrm{mL}$ Gal $\alpha 3 \mathrm{LN}-\mathrm{HSA}$. a, b Percentage of antigen-specific $\mathrm{CD}^{+}$and $\mathrm{CD}^{+} \mathrm{T}$ cells, respectively, in immunized mice. c, d Percentage of $\mathrm{CD}^{+}$and $\mathrm{CD}^{+} \mathrm{T}$ cells, respectively, in immunized-challenged mice. e, $\mathbf{f}$ Percentage of memory $\mathrm{CD}^{+} \mathrm{CD}_{4} 4^{+}$and $\mathrm{CD} 8^{+} \mathrm{CD} 44^{+} \mathrm{T}$ cells, respectively, in immunized-challenged mice. One-way analysis of variance (ANOVA) compared with naive group was obtained for the immunized groups; Two-way ANOVA compared with the naive group was obtained for the immunized-challenged groups; ${ }^{*} p<$ $0.05 ;{ }^{* *} p<0.01 ;{ }^{* * *} p<0.0001$. Error bars indicate S.E.M. of triplicate determinations

To address whether the anti-a-Gal Abs elicited by immunization with Gala3LN-HSA+/-LMPLA are trypanolytic, sera from both animal groups were incubated with TCTs for $30 \mathrm{~min}$ at $37^{\circ} \mathrm{C}$, without complement, and live and dead parasites were manually counted (Fig. 4b). In the Gala3LN-HSA-vaccinated group, we observed $42.3 \%( \pm 3.9)$ and $27.4 \%( \pm 1.0)$ parasite deaths at $1: 2$ and 1:20 serum dilutions, respectively. Likewise, in the Gala3LNHSA+LMPLA-immunized group, we observed 39.6\% $( \pm 3.13)$ and $18.9 \%( \pm 3.1)$ parasite deaths at 1:2 and 1:20 dilutions, respectively, suggesting a dose-dependent effect. A naive mouse serum (NMS) was used as negative control and a low parasite death $(6.0 \%, \pm 0.1)$, not significantly different from that of the live parasite control (medium alone) $(6.1 \%, \pm 1.0)$, was observed. This result was further corroborated by the very low binding to the parasite surface of
anti-a-Gal Abs purified from mice immunized with HSA+LMPLA (Fig. 4c). As positive controls, parasites were incubated with 4\% formaldehyde or Ch anti-a-Gal Abs, resulting in $100 \%$ and $64.6 \%$ $( \pm 0.74)$ parasite deaths, respectively (Fig. $4 \mathrm{~b})$. It is important to point out that the $\mathrm{Ch}$ anti- $\mathrm{a}-\mathrm{Gal}$ Ab-mediated trypomastigote lysis occurred in the absence of complement, corroborating therefore previous observations. ${ }^{22}$ Similarly, the parasite lysis caused by antiserum from mice immunized with Gala3LN-HSA+/-LMPLA was complement independent.

To assess whether anti- $a-G a l$ Abs elicited by immunization with Gala3LN-HSA+/-LMPLA recognize a-Gal-rich domains on the TCT surface, we performed immunoaffinity purification of these Abs using nitrocellulose-immobilized Gala3LN-HSA, followed by confocal microscopy. The murine (mu) anti-a-Gal lgG Abs from animals immunized with Gala3LN-HSA+/-LMPLA strongly recognize speckled regions toward the parasite's anterior end and mostly on the flagellar membrane (Fig. 4c, second and third panel rows from the top, yellow arrowheads). These domains partially colocalize with Bandeiraea (Griffonia) simplicifolia isolectin IB4, which has a broad specificity toward terminal nonreducing a-Gal residues $^{41}$ (Fig. 4c, second and third row from the top, last panel, yellow arrowheads). Conversely, human $\mathrm{Ch}$ anti-a-Gal Abs exhibited an extensive colocalization with IB4 lectin (Fig. 4c, Controls, fourth panel, yellow arrowheads), strongly indicating that both are recognizing a more diverse array of a-Gal glycotopes on the parasite surface as compared to the murine anti-a-Gal Abs. Some areas on the parasite surface located toward the flagellum, however, did not have any colocalization with IB4 (Fig. 4C, Controls, fourth panel, red arrowheads). As negative controls, we used natural anti-a-Gal Abs immunopurified from HSA+LMPLAimmunized or naive animals. These natural anti-a-Gal Abs showed very low binding to the parasite-specific a-Gal glycotopes (Fig. 4c, bottom rows).

The $a-G a l$ vaccine in combination with the adjuvant LMPLA induce upregulation of cytokines and chemokines following vaccination and T. cruzi infection

The production of different cytokines and chemokines is essential for a protective cell-mediated immune response against $T$. cruzi infection. ${ }^{42}$ Thus we evaluated whether immunization with Gala3LNHSA+/-LMPLA or HSA+LMPLA could elicit a cell-mediated immune response, by using a bead-based Multiplex assay. First, a panel of 32 mouse cytokines, chemokines, and growth factors were analyzed in sera from immunized and $T$. cruzi-challenged mice at the experimental endpoint (32 dpi). In comparison to the challenged group, only the group of mice vaccinated with Gala3LN-HSA in combination with the adjuvant LMPLA displayed significantly higher levels of serum cytokines, particularly, IL-2, IL-4, IL-9, IL-15 (1.3-3.1-fold change), chemokine $\mathrm{C}-\mathrm{C}$ chemokine motif ligand 3 (CCL3; 1.5 -fold change), and growth factor vascular endothelial growth factor (VEGF; 4-fold change) (Supplementary Table 1). Furthermore, we observed no significant upregulation of these molecules in the Gala3LN-HSA- or HSA+LMPLA-immunized groups. These results suggest that the a-Gal-vaccine, in the presence of the adjuvant LMPLA, could induce the secretion of these cytokines, chemokines, and growth factor, following immunization and acute $T$. cruzi infection.

Gala3LN-HSA vaccination elicits antigen-specific $\mathrm{CD}^{+}{ }^{+} \mathrm{T}$ cell response

Next, we investigated whether Gala3LN-HSA+/-LMPLA could induce antigen-specific $\mathrm{CD}^{+}$and $\mathrm{CD}^{+} \mathrm{T}$ cells. To this end, splenocytes from a1,3GalT-KO mice vaccinated with Gala3LN-HSA, Gala3LN-HSA+LMPLA, or naive control group were stimulated in vitro with $20 \mu \mathrm{g} / \mathrm{mL}$ of Gala3LN-HSA antigen. We found a very significant $(p \leq 0.0001)$ increase of antigen-induced $\mathrm{CD}^{+}$and $\mathrm{CD}^{+} \mathrm{T}$ cells in both immunized (Fig. $5 \mathrm{a}, \mathrm{b}$ ), and immunized- 

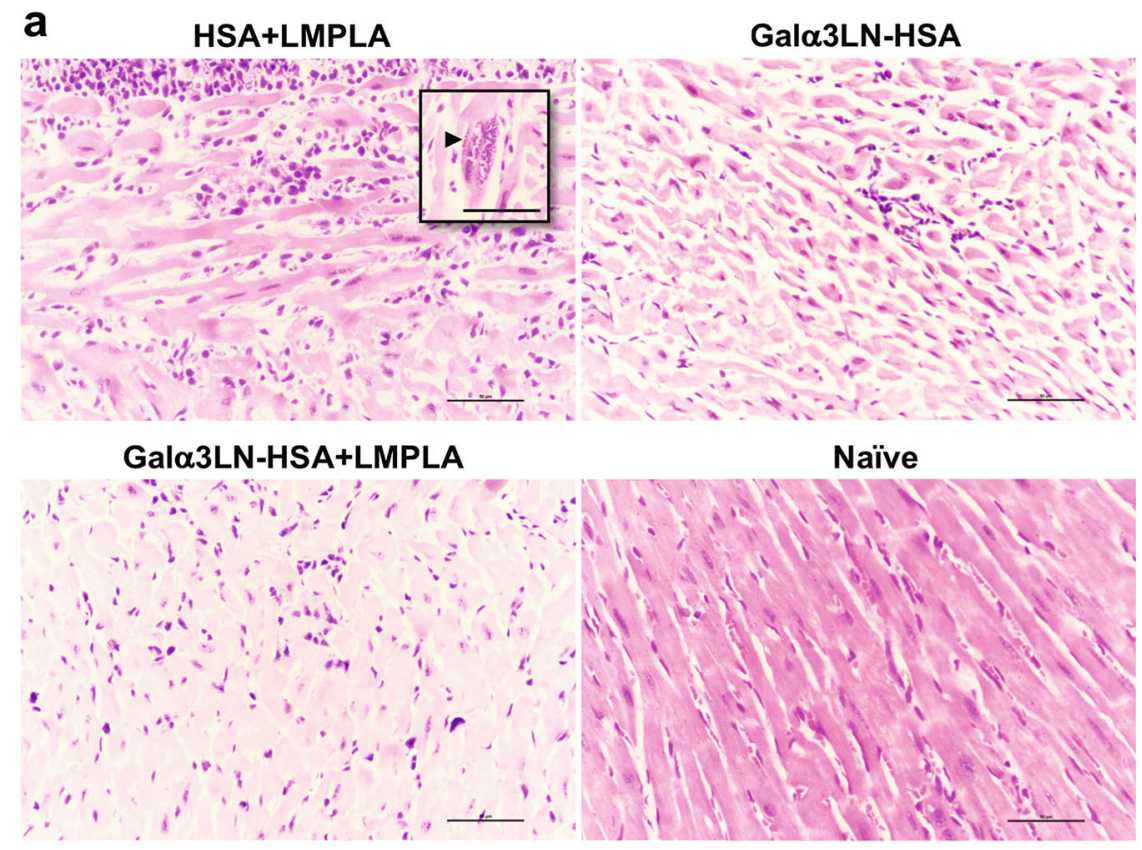

b

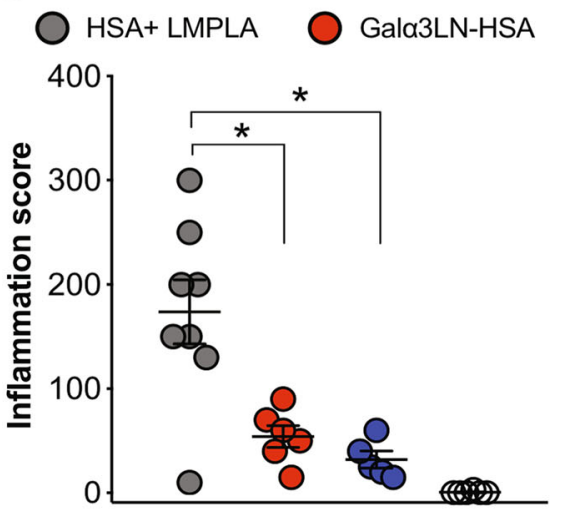

C
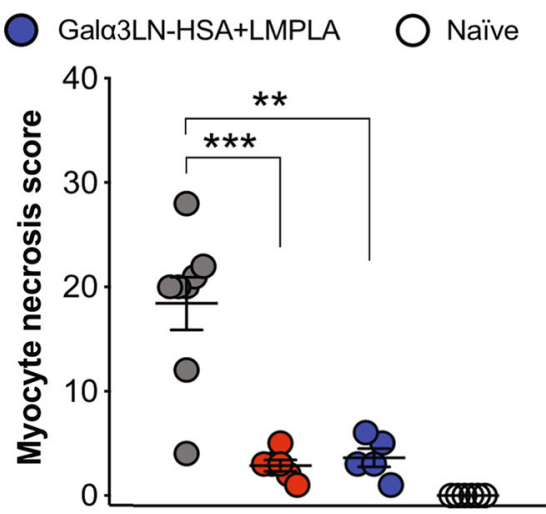

Treatment Group

Fig. 6 Histopathology analysis. a Micrographs of heart sections harvested at the endpoint and stained with hematoxylin and eosin. Inset, arrowhead indicates an amastigote nest. b Myocardial inflammatory and mononuclear cell infiltrates were manually scored. c Myocyte necrosis was manually counted in 25 fields $(\times 400)$. Magnification $\times 40$, bar $100 \mu \mathrm{m}$. Statistical significance was calculated by unpaired twotailed Mann-Whitney test, comparing Gal $\alpha 3 \mathrm{LN}-\mathrm{HSA}+/-$ LMPLA group to HSA+LMPLA group. $p$ values indicate the significance ${ }^{*} p<0.05 ;{ }^{* *} p<$ $0.01{ }^{* * *} p<0.001$

challenged mice (Fig. 5c, d) but not in the naive control group. Next, we investigated whether antigen-specific $\mathrm{CD}^{+}$and $\mathrm{CD} 8^{+}$ $\mathrm{T}$ cells differentiated into memory $\mathrm{CD}_{4} 4^{+} \mathrm{T}$ cells in a-Galimmunized and parasite-challenged mice. Gala3LN-HSA but not Gala3LN-HSA+LMPLA generated a small but significant expansion of antigen-specific memory $\mathrm{CD} 4^{+} \mathrm{CD} 44^{+} \mathrm{T}$ cells (Fig. 5e). On the other hand, no significant increase of memory $\mathrm{CD} 8^{+} \mathrm{CD} 44^{+} \mathrm{T}$ cells were observed with either vaccine (Fig. 5f). Taken together, these results indicate the ability of the a-Gal-based vaccine alone to generate antigen-specific memory $\mathrm{CD}^{+} \mathrm{T}$ cells, critical for an effective protective anti-a-Gal IgG Ab immunity against $T$. cruzi infection. ${ }^{15,19}$

a-Gal-vaccinated animals have significantly decreased cardiac inflammation; myocyte necrosis; and $\mathrm{CD}^{+}{ }^{+}, \mathrm{CD}^{+}$, and $\mathrm{CD}^{+}{ }^{+}$cell infiltration

At the experimental endpoint (32 dpi), we also performed histopathological analysis of cardiac inflammation and myocyte necrosis in the three immunized and challenged groups. The number of mononuclear cells, including lymphocytes and macrophages, was counted in the ventricle sections. The necrosis of individual myocytes was also manually quantified. Figure 6a shows representative micrographs of heart sections of animals from the HSA+LMPLA, Gala3LN-HSA, or Gala3LN-HSA+LMPLA groups. Clearly, animals in the HSA+LMPLA group exhibited much higher cardiac inflammation and myocyte necrosis than animals vaccinated with Gala3LN-HSA+/-LMPLA. Moreover, amastigote nests were observed in most animals of the HSA+LMPLA group but not in any animal vaccinated with Gala3LN-HSA+/-LMPLA (Fig. 6a, inset). Quantification of the cardiac inflammation and myocyte necrosis shows significant differences between animals of the HSA+LMPLA group and those vaccinated with Gala3LN-HSA+/-LMPLA (Fig. 6b). However, no significant differences were observed between the two latter groups, indicating that LMPLA adjuvant did not provide any additional protection. Moreover, heart sections from animals immunized with Gala3LN-HSA+/-LMPLA or HSA-LMPLA control, subsequently challenged with $T$. cruzi, were also evaluated for 
infiltration of $\mathrm{CD}^{+}, \mathrm{CD}^{+}$, and $\mathrm{CD}^{+}{ }^{+} \mathrm{T}$ cells at the experimental endpoint. Corroborating with the inflammation data (Fig. 6), a1,3GalT-KO mice immunized with the a-Gal-based vaccine, in the presence or not of an adjuvant, exhibited a much lower number of infiltrating $\mathrm{CD}^{+}{ }^{+} \mathrm{CD}^{+}$, and $\mathrm{CD}^{+}{ }^{+}$cells (Supplementary Figure 4).

\section{DISCUSSION}

As globalization increases, so have the reported cases of individuals infected with $T$. cruzi, with a rising number living in nonendemic regions such as the U.S. and Europe. ${ }^{43,44}$ Despite considerable efforts to control insect vectors ${ }^{45}$ and development of more effective chemotherapeutics ${ }^{3}$ and diagnostics, ${ }^{46,47}$ an effective prevention of $C h D$ remains a challenge worldwide. Thus a prophylactic $\mathrm{ChD}$ vaccine is of paramount necessity considering that an estimated 25 million people are at risk of contracting the disease just in Latin America ${ }^{48}$ and many thousands more in nonendemic areas, including several regions in the U.S. and Europe. ${ }^{44,49}$

In recent years, several experimental vaccines based primarily on $T$. cruzi recombinant proteins and peptides and DNA have been developed. ${ }^{6,12,50}$ Although a few of these vaccines are highly effective in protecting mice against laboratorial parasite strains, there is no evidence so far that their target epitopes are conserved among the six parasite genotypes and a multitude of field isolates. ${ }^{9}$ Thus far, none of these vaccines have moved to clinical trials. One key obstacle is the extensive diversity of major parasite surface proteins, encoded mainly by three multigene families (i.e., mucins, TSs, and MASPs). ${ }^{10,51-53}$ The highly variable protein coat, owing to the simultaneous and differential expression of hundreds of sequence-coding genes in the two mammal-dwelling parasite stages and different strains ${ }^{10,51-53}$, hinders the development of an effective and universal vaccine targeting major parasite proteins.

Glycoconjugates, on the other hand, have recently become increasingly attractive molecular targets against trypanosomatids such as T. cruzi and Leishmania spp., both as biomarkers and potential vaccine candidates. ${ }^{24,29,33,34,55,56}$ In T. cruzi, its complex carbohydrate-rich surface coat contains GPI-anchored glycoproteins such as mucins, which exhibit the immunodominant glycotope Gala1,3Galß1,4GlcNAc, linked mostly to a threonine residue. $^{15}$ This highly immunogenic glycotope elicits lytic and protective anti-a-Gal Abs, which in turn controls the parasitemia in both the acute and chronic phases of the disease. ${ }^{15,18-21}$ With this in mind, we have used the linear trisaccharide, bound to human albumin, Gala3LN-HSA, which is almost identical to the native glycotope found on tGPI-mucins, except for the GIcNAc anomeric configuration, which is a on the latter. To mimic a human response, the efficacy of the a-Gal-containing vaccine (Gala3LNHSA) was evaluated in the a1,3GalT-KO mouse model, which, in comparison to WT mice, does not express terminal, linear a-Gal glycotopes. ${ }^{35,36}$ As a result, a1,3GalT-KO mice produce high levels of anti-a-Gal Abs when infected with T. cruzi. ${ }^{57}$

First, we investigated the immune response differences between the C57BL/6 a1,3GalT-KO and WT mice infected with $T$. cruzi, keeping in mind the similarities that the former have with humans and Old-World nonhuman primates in that they elicit high-affinity Abs to the linear a-Gal glycotope. We observed that a1,3GalT-WT mice were unable to produce a robust immune response against $T$. cruzi via generation of protective anti-a-Gal Abs and a balanced serum cytokine profile, severely affecting their survival rate. In contrast, the a1,3GalT-KO animals could more effectively control the infection by decreasing parasitemia, likely due to the production of high levels of anti-a-Gal Abs and a balanced $\mathrm{T}$ helper type 1 (Th1)/Th2 cytokine response. We speculate that the latter could be explained by a mechanism of anti-a-Gal-mediated antigen-presenting cell (APC) targeting, as proposed by Uri Galili and collaborators. ${ }^{58-60}$ For instance, these authors demonstrated that IgG anti- $a-G a l$ Abs produced against $a-$
Gal-glycolipids loaded onto the surface of liposomes containing encapsulated chicken ovalbumin (OVA) could opsonize these antigens via Fc-gamma receptor (FcyR) present on the surface of APCs such as dendritic cells, leading to improved transport, processing, and presentation of the immunodominant OVAderived SIINFEKL peptide to $\mathrm{CD}^{+} \mathrm{T}$ cells. This resulted in an increased immunogenicity of the vaccine and induction of IFN- $\gamma$ by both $\mathrm{CD}^{+}$and $\mathrm{CD}^{+}{ }^{\mathrm{T}}$ cells. ${ }^{59}$ The same mechanism was observed by intradermal injection of a-Gal-containing nanoparticles in the skin of a1,3-GalT-KO mice, resulting in the upregulation of various cytokine and chemokine genes, including VEGF, fibroblast growth factor, IL-1, platelet-derived growth factor, and colony-stimulating factor (CSF). ${ }^{60}$ In our current study, the induction of anti-a-Gal Abs by TCTs in a1,3-GalT-KO mice, but not in a1,3-GalT-WT animals, could have resulted in improved presentation of parasite-derived peptides to $\mathrm{CD}^{+}$and $\mathrm{CD}^{+}$ T cells, ensuing the production of Th1 and Th2 cytokines required for an effective protective response against the parasite.

Furthermore, the anti-a-Gal Abs, purified from a1,3GalT-KO mice, were lytic to TCTs in a complement-independent manner, as previously demonstrated for human $\mathrm{Ch}$ anti-a-Gal Abs. ${ }^{22}$ We have also shown here that purified murine anti-a-Gal lgG Abs could effectively block host cell infection and intracellular proliferation of the parasite. In sum, a1,3GalT-KO and a1,3GalT-WT mice clearly demonstrated an opposite behavior regarding the development of the infection and immune response in the acute phase of ChD. Our data support previous findings that acutely $T$. cruzi-infected a1,3GalT-KO mice exhibit lower parasitemia and increased production of anti-a-Gal Abs, ${ }^{57}$ which can be key to eliminate circulating parasites and control the disease. ${ }^{26,61}$

Since a1,3GalT-WT demonstrated to be a poor model to test protection against the heavily glycosylated T. cruzi TCT forms, we proceeded to test our a-Gal-based vaccine candidate (Gala3LN-HSA+/-LMPLA) in the a1,3GalT-KO mouse model. Evidently, high protection was observed at early infection stages, the parasite burden was drastically reduced, while the survival rate and animal weight were stable throughout the course of the experiment. To corroborate these results, the parasite systemic dissemination on selected individual organs was analyzed by qPCR. Interestingly, T. cruzi CL Brener-luc strain is not only myotropic but also localize to a number of tissues, particularly colon and stomach. ${ }^{40,62}$ Here we observe a decrease in parasitic burden $>90 \%$ in all harvested tissues (i.e., heart, lung, spleen, skeletal muscle, intestine, liver, stomach, colon) from either Gala3LN-HSA- or Gala3LN-HSA+LMPLA-vaccinated mice when compared with the HSA+LMPLA control group.

Next, we evaluated the humoral immune response in a1,3GalTKO mice immunized with Gala3LN-HSA, Gala3LN-HSA+LMPLA, or HSA+LMPLA. Both aGal-vaccinated groups elicited more IgG1 and IgG2b than IgG3 Abs. Our results are similar to those from a recent study using C57BL/6 a1,3GalT-KO mice immunized with the NGP Gala3LN-BSA, in which high levels of $\lg G 1, \lg G 2 b$, and $\lg G 3$ Abs were observed. ${ }^{32}$ Previous studies have shown that $\operatorname{lgG} 1$ and $\lg \mathrm{g} 2 \mathrm{~b}$ are associated with protection against $T$. cruzi infection. ${ }^{63,64}$ Furthermore, in an effort to improve the humoral immune response, Gala3LN-HSA was formulated with the LMPLA adjuvant. $^{65}$ It is recognized that LMPLA acts inducing a Th1-biased immune and $A b$ responses, rich in $\operatorname{lgG} 1$ and $\lg G 3$ isotypes in humans, ${ }^{66}$ and preferentially lgG2a in mice. ${ }^{67}$ These lgs have the ability to opsonize and destroy infected cells and enhance the production of $\mathrm{CTL} \mathrm{CD8}{ }^{+} \mathrm{T}$ cells (reviewed in ref. ${ }^{66}$ ). Here the addition of LMPLA adjuvant significantly increased the levels $\lg \mathrm{G} 1$, IgG2b, and IgG3 isotypes compared to Gala3LN-HSA alone, in which no significant levels of IgG3 were detected. Since C57BL/ 6 mice do not express lgG2a due to a genetic mutation, ${ }^{68}$ this immunoglobulin was not measured in our experiments.

Furthermore, we could not detect a significant production of $\operatorname{IgA}$ in either the Gala3LN-HSA- or the Gala3LN-HSA+MPLA- 
vaccinated group, even after depletion of IgG Abs that could compete for the binding to the immobilized Gala3LN-HSA antigen on CL-ELISA. This result corroborates the previous observation by LaTemple and Galili ${ }^{69}$ that IgA Abs are not elicited following immunization of C57BL/6 a1,3GalT-KO mice with an a-Galcontaining antigen. Moreover, in our study, we also could not detect any IgE Abs in the a-Gal-vaccinated groups, even following depletion of $\lg G$ Abs. The absence of $\lg E$ Abs is noteworthy, because it minimizes concerns about induction of autoimmune- or allergy-related lgE following vaccination with either a-Gal-vaccine formulation tested here. IgE anti- $\mathrm{a}-\mathrm{Gal}$ Abs are linked to anaphylactic reactions to non-primate mammalian meat and other types of food ${ }^{70}$ and to recombinant monoclonal Abs (e.g., Cetuximab). ${ }^{71}$ In this case, the a-Gal glycotopes are in complextype $\mathrm{N}$-glycans containing terminal nonreducing a-Gal residues 1,3 -linked to $N$-acetyllactosamine (Gala1,3Gal $\beta 1,4$ GlcNAc $\beta-R$ ). By contrast, in $T$. cruzi tGPI-mucins the a-Gal glycotopes are found in the linear O-glycan trisaccharide, Gala1,3Galß1,4GlcNAca, or in asyet uncharacterized branched $O$-glycans, both directly linked to threonine or serine residues. ${ }^{15}$ In this study, the Gala3LN glycotope is covalently linked to HSA via a 3-atom spacer, thus more closely resembling a short $O$-glycopeptide than a long complex-type $\mathrm{N}$-glycopeptide. We speculate that the differential presentation of a-Gal-containing $N$ - and $O$-glycopeptides by activated $B$ cells via major histocompatibility complex (MHC) class II to $\mathrm{CD}^{+} \mathrm{T}$ cells could lead to distinct isotype switching (IgM to $\lg G$ or $\lg M$ to $\lg E)$.

The specificity and lytic power of murine anti-a-Gal Abs being produced upon vaccination with Gala3LN-HSA+/-LMPLA was further explored by treating the target glycotope with agalactosidase. With the removal of terminal a-Gal residues, the reactivity in CL-ELISA of the serum from mice immunized with Gala3LN-HSA+/-LMPLA significantly decreases ( 65\%). The residual reactivity could be due to Abs to the HSA moiety, which was corroborated by the strong total IgG reactivity observed in animals immunized with HSA+LMPLA. Moreover, sera from mice immunized with either vaccine formulation killed the parasites in $30 \mathrm{~min}$, in a dose-dependent manner, in the absence of complement. This corroborates the idea that binding of $\mathrm{Ch}$ anti$\mathrm{a}-\mathrm{Gal}$ Abs to the parasites destabilizes the plasma membrane by clustering abundant a-Gal-containing glycoproteins, such as tGPImucins, and disrupt the surface coat, causing blebs, agglutination and, ultimately, death. ${ }^{22}$ This mechanism has been well established in T. cruzi TCTs and, more recently, has also been proposed in Leishmania major. ${ }^{33}$ The labeling of TCTs with purified murine anti-a-Gal Abs is predominantly located to the parasite flagellum and resembles a "patchwork quilt" as recently observed by Lantos et al. ${ }^{72} \mathrm{~A}$ similar but more extensive labeling pattern was observed with purified $\mathrm{Ch}$ anti-a-Gal Abs, indicating that other $\mathrm{a}-\mathrm{Gal}$ specificities are present in chronic ChD. Indeed, besides the linear Gala1,3Galß1,4GlcNAca trisaccharide, tGPI-mucins encompass several as-yet uncharacterized a-Gal-containing branched $\mathrm{O}$-glycans, which are also strongly recognized by $\mathrm{Ch}$ anti-a-Gal Abs. ${ }^{15}$ IB4-Lectin has broad specificity toward terminal nonreducing a-Gal residues, primarily recognizing Gala1,3- and, to a lesser extent, Gala1,6-containing oligosaccharides, although other a-Gal linkages should be considered. ${ }^{41}$ This might explain the more extensive and homogenous recognition of parasite membrane by this lectin than Gala3LN-HSA-specific anti-a-Gal Abs.

In this study, at $32 \mathrm{dpi}$, we observed a significant upregulation of IL-2, IL-4, IL-9, IL-15, CCL3, and VEGF in the serum of a1,3GalT$\mathrm{KO}$ mice immunized with Gala3LN-HSA only in the presence of the adjuvant LMPLA. Interestingly, no significant increase was exhibited in the Gala3LN-HSA or HSA+LMPLA immunized-challenged groups. Cytokines and chemokines play an important role in the protective immune response generated against $T$. cruzi infection. ${ }^{73}$ For instance, co-administration of a plasmid DNA encoding murine IL-15 together with $T$. cruzi TS DNA vaccine increased long-term protection against $T$. cruzi lethal infection. ${ }^{74}$ IL-15 has also been associated with survival and proliferation of memory $\mathrm{CD}^{+}$and $\mathrm{CD}^{+}{ }^{+}$cells. ${ }^{74,75}$ In addition, CC chemokine ligands CCL3 enhance the uptake of $T$. cruzi by macrophages, promoting nitric oxide that exerts trypanocidal activity, regulating parasite replication. ${ }^{76}$ Furthermore, VEGF $\beta$, a family member of VEGF, has been demonstrated to be important against heart failure. ${ }^{77}$ IL-2 and IL-4 are known to promote the generation of IL-9 cytokine. ${ }^{78}$ However, the role of IL-9 in T. cruzi or $\mathrm{ChD}$ has not been studied. Altogether, these results indicate that the cytokine and chemokine response could be elicited by the $a-$ Gal vaccine plus the adjuvant LMPLA, which is a strong activator of Toll-like receptor 4-mediated signaling pathway ${ }^{65,79}$ and not by the carrier protein HSA or adjuvant alone, thus modulating an effective protective host immune defense against infection. However, we do not discard the possibility that this combination may lead to excessive inflammation, affecting the survival of Gala3LN-HSA+LMPLA immunized mice, as observed here.

Previous studies showed that mice deficient in the MHC (MHC I and $\mathrm{MHC}$ II) ${ }^{80}$ or in both $\mathrm{CD}^{+}$and $\mathrm{CD}^{+} \mathrm{T}^{\mathrm{T}}$ cells ${ }^{81,82}$ suffered high mortality and increased parasitemia following $T$. cruzi infection. Furthermore, during parasite infection, $\mathrm{CD}^{+}{ }^{+} \mathrm{T}$ cells are capable of secreting Th1 cytokines (e.g., IFN- $\gamma$ ), which are crucial for macrophage activation and subsequent inhibition of the parasite. These cytokines can also induce the expansion of cytotoxic CD8 ${ }^{+}$ T cells, which destroy infected cells. ${ }^{42}$ Therefore, the production of $\mathrm{CD}^{+}$and $\mathrm{CD}^{+}{ }^{+}$cell-mediated responses is considered to be essential for the control and protection against $T$. cruzi infection. $^{12,83}$ Here we evaluated whether antigen-specific $\mathrm{CD}^{+}$and $\mathrm{CD}^{+}{ }^{+}$cells were induced by Gala3LN-HSA+/-LMPLA vaccination before and after T. cruzi challenge. We observed a statistically significant cell-mediated immune response led by the production of $\mathrm{CD}^{+}$and $\mathrm{CD}^{+} \mathrm{T}$ cells before and after parasite infection. Moreover, following stimulation with Gala3LN-HSA, we could observe a small but significant presence of $\mathrm{CD} 4^{+} / \mathrm{CD} 44^{+}$but not of $\mathrm{CD}^{+} / \mathrm{CD}_{4} 4^{+} \mathrm{T}$ lymphocytes in the spleen of animals vaccinated and challenged, indicating specific memory $\mathrm{CD} 4^{+} \mathrm{T}$ cells. Whether these cells are recognizing only HSA-derived peptides, Gala3LNcontaining glycopeptides, or both remains to be determined. However, since we observed a robust isotype switching (from IgM to $\mathrm{lgG}$ ) following immunization, characterized by significant production of $\lg G 1, \lg G 2 b$, and, to a lesser extent, $\lg G 3$, our data strongly suggest engagement of $\mathrm{CD}^{+} \mathrm{T}$ cells via recognition of both peptides and glycopeptides presented by MHC II on the activated $B$ cells. ${ }^{84,85}$ Thus we propose that production of murine anti-a-Gal lgG Abs specific to the Gala3LN glycotope in a1,3GalT$\mathrm{KO}$ mice occurs through the established T cell-dependent $\mathrm{B}$ cell memory mechanism previously demonstrated for bacterial glycoproteins, glycopeptides, and zwitterionic polysaccharides (reviewed in ref. ${ }^{85}$ ).

High parasitemia, uncontrolled inflammation, and necrosis of heart myocytes are some of the main factors that influence the development of myocardial dysfunction in ChD patients. ${ }^{86}$ In this study, histopathological analyses of heart tissue from mice vaccinated with Gala3LN-HSA+/-LMPLA showed significant downregulation of inflammation and low levels of myocyte necrosis, when compared to the HSA-LMPLA group. Furthermore, we observed a much lower infiltration of $\mathrm{CD}^{+}, \mathrm{CD}^{+}$, and $\mathrm{CD} 8^{+}$ $T$ cells in the cardiac tissue of animals vaccinated with Gala3LNHSA+/-LMPLA, corroborating therefore the protective immune response generated by the two vaccine formulations.

In conclusion, here we performed the first proof-of-concept studies, which demonstrate the efficacy of two a-Gal-based vaccine formulations for the prophylactic immunization against experimental acute $T$. cruzi infection. To this end, we validated the a1,3GalT-KO mouse model, which closely resembles the major protective human anti-glycan response observed in $\mathrm{ChD}$. This is a 
suitable experimental model to evaluate more effective prophylactic and therapeutic a-Gal-based vaccines.

\section{METHODS}

\section{Ethics statement}

Human serum samples used for preparation of the ChD human serum pool (ChHSP) and for purification of anti-a-Gal Abs used in this study were obtained from chronic adult ChD patients from the Hospital Clinic of Barcelona (HCB), Barcelona Institute for Global Health (ISGlobal), Barcelona, Spain and were kindly donated by Dr. Joaquim Gascón. The Institutional Review Board (IRB) protocol was approved by the IRB Committee of HCB, and all $\mathrm{ChD}$ patients signed an informed consent form.

All animal procedures were performed according to $\mathrm{NIH}$ guidelines and the appropriate protocol (A-201211-1) approved by the Institutional Animal Care and Use Committee (IACUC) at the University of Texas at El Paso (UTEP).

Mice

C57BL/6 a1,3-Galactosyltransferase-knockout (a1,3GalT-KO) mice ${ }^{35,36}$ were kindly donated by Professor Peter J. Cowan, St. Vincent's Hospital Melbourne and University of Melbourne, Australia. Mice were bred and maintained under biosafety level 2, pathogen-free conditions at the Laboratory Animal Resources Center at UTEP. Six-to-ten-week-old female a1,3GalT-KO mice were used for all experiments. WT (a1,3GalT-WT) C57BL/ 6 mice (Jackson Laboratories, Bar Harbor, ME) were also used.

Parasites and mammalian-cell culture

T. cruzi Y strain $^{87}$ was obtained from ATCC (Manassas, VA), and the $\mathrm{CL}$ Brener clone, ${ }^{88,89}$ expressing red-shifted firefly luciferase (CL Brener-luc), was kindly donated by Professor John Kelly (London School of Tropical Medicine and Hygiene, UK). Mammalian TCT forms were obtained by infecting rhesus monkey kidney epithelial LLC-MK2 cells (ATCC) with either axenic metacyclic trypomastigotes or mouse-derived bloodstream trypomastigotes at a multiplicity of infection (m.o.i.) of 10 for $2 \mathrm{~h}$ at $37^{\circ} \mathrm{C}$. Cells were maintained in Dulbecco's modified eagle medium (DMEM), supplemented with $10 \%$ heat-inactivated fetal bovine serum (FBS) (Gibco, Thermo Fisher Scientific, Waltham, MA) and $1 \%$ penicillin-streptomycin at $37{ }^{\circ} \mathrm{C}$ with $5 \% \mathrm{CO}_{2}$ atmosphere. TCTs were collected, washed with sterile PBS by centrifugation $\left(1000 \times g, 10 \mathrm{~min}\right.$, at $\left.4{ }^{\circ} \mathrm{C}\right)$, and prepared for mouse infections and other experiments. To devoid the parasites of sialic acid, infected cells were washed with DMEM with $0.2 \%$ BSA and $1 \%$ penicillin-streptomycin and incubated for $2 \mathrm{~h}$, at $37^{\circ} \mathrm{C}$, as described..$^{22}$

\section{Parasitemia and survival rate determination}

Five $\mu \mathrm{L}$ of blood, obtained by venipuncture of the mouse tail, was diluted in $18 \mu \mathrm{L}$ of $0.89 \%$ ammonium chloride in PBS, and TCTs ( $Y$ strain) were counted on a hemocytometer. Data were plotted as the number of TCTs per microliter of blood. Mice were evaluated for survival daily. Survival rates were plotted as Kaplan-Meier curves.

Immunopurification of human and murine anti-a-Gal antibodies Murine anti-a-Gal Abs were obtained from a1,3GalT-KO mice infected with CL Brener-luc. Immunopurification of both human and murine anti-a-Gal Abs was performed as described, ${ }^{19}$ using Synsorb 115 beads, containing the Galili trisaccharide Gala1,3Galß1,4GIcNAc (Gala3LN) covalently linked to silica particles $(0.88 \mathrm{pmol}$ oligosaccharide/g Synsorb; ChemBiomed, Edmonton, Canada). Beads were extensively washed with PBS-0.5 M NaCl to remove non-anti-a-Gal IgG (unbound IgG). Murine anti-a-Gal Abs were eluted from the Synsorb 115 with $0.1 \mathrm{M}$ glycine- $\mathrm{HCl}$ or $50 \mathrm{mM}$ citric acid pH 2.8 and immediately neutralized with $1 \mathrm{M}$ Tris, $\mathrm{pH}$ 8.0. Both the unbound IgG and the anti-a-Gal Ab fractions were dialyzed against PBS, overnight $(\mathrm{O} / \mathrm{N})$, at $4{ }^{\circ} \mathrm{C}$, concentrated in a $30-\mathrm{kDa}$ Amicon Ultra-15 Centrifugal Filter Unit (Millipore Sigma, Burlington, MA), and stored at $-20^{\circ} \mathrm{C}$ until use.

\section{In vitro host cell infection assays}

LLC-MK2 cells were maintained as described above and $\mathrm{Y}$ strain TCTs were used for in vitro infection. Briefly, cells were seeded on 15-mm microscope coverslips in 24-well tissue culture plates (Corning Costar, Thermo Fisher
Scientific). After incubation at $37^{\circ} \mathrm{C}$ in humidified atmosphere containing $5 \% \mathrm{CO}_{2}, \mathrm{O} / \mathrm{N}$, non-adherent cells were washed off. Adherent cells were infected with $Y$ strain TCTs $(m . o . i .=10)$ for $2 \mathrm{~h}$, at $37^{\circ} \mathrm{C}$. During infection, purified murine anti-a-Gal lgG Abs were added at 100, 10, and $1 \mu \mathrm{g} / \mathrm{mL}$. Unbound IgG fraction (containing non-anti-a-Gal IgG Abs) and medium alone were used as negative controls. After infection, parasites in the cell culture medium supernatant were counted for 8 consecutive days. Infected adherent cells were then fixed in $4 \%$ formaldehyde and permeabilized with $0.2 \%$ Triton X-100 in PBS for $5 \mathrm{~min}$ on ice. Cells were washed and blocked with $1 \%$ BSA-PBS for $30 \mathrm{~min}$ at room temperature (RT). Internalized parasites were stained with $1 \mu \mathrm{g} / \mathrm{mL}$ of 4,6-diamidino-2phenylindole (Invitrogen, Carlsbad, CA) and immunolabeled with purified murine anti-a-Gal Abs $(1 \mu \mathrm{g} / \mathrm{mL})$ for $2 \mathrm{~h}$ at RT. Reactivity of murine anti-aGal IgG with intracellular parasites was detected by incubation with goat anti-human $\operatorname{lgG}(2.2 \mu \mathrm{g} / \mathrm{mL})$ (Thermo Fisher Scientific) for $1 \mathrm{~h}$, at RT, followed by Alexa Fluor 488 donkey anti-goat $\mathrm{lgG}(10 \mu \mathrm{g} / \mathrm{mL}$ ) (Thermo Fisher Scientific) for $1 \mathrm{~h}$ at RT. Visualization of at least 1000 cells was done using a BD Pathway 855 Imager (BD Bioscience). Experiment was performed in triplicate determinations.

Preparation of liposomes and Gala3LN-HSA immunizations Liposomal-monophosphoryl lipid A (LMPLA) were prepared as described. ${ }^{65}$ Briefly, 1,2-dimyristoyl-sn-glycero-3-phosphocholine, cholesterol, and 1,2dimyristoyl-sn-glycero-3-phospho-rac-(1-glycerol) (Avanti Polar Lipids, Alabaster, $\mathrm{AL}$ ) were dissolved in freshly distilled chloroform stabilized with $0.75 \%$ ethanol at a molar ratio of (9:7.5:1) along with monophosphoryl lipid A (Sigma-Aldrich, St. Louis, MO) for a final concentration of $100 \mu \mathrm{g} / \mathrm{mL}$. Liposomes were dried under nitrogen stream and placed $\mathrm{O} / \mathrm{N}$ in a desiccator containing silica-gel desiccant beads (Thermo Fisher Scientific). Liposomes were then resuspended for a final concentration of $10 \mu \mathrm{g} /$ $200 \mu \mathrm{L}$ of sterile PBS, pH 7.4, containing $20 \mu \mathrm{g}$ Gala3LN-HSA (3-atom spacer, NGP2334, Dextra Laboratories, Reading, UK) or $20 \mu \mathrm{g}$ recombinant HSA (Thermo Fisher Scientific), then filtered using a $0.2-\mu \mathrm{m}$ disc filter (Thermo Fisher Scientific). For immunizations in the absence of LMPLA, a stock solution of $1 \mathrm{mg} / \mathrm{mL}$ Gala3LN-HSA in sterile, deionized milli-Q water was prepared and kept in $200-\mu \mathrm{L}$ aliquots at $-20^{\circ} \mathrm{C}$ until use.

\section{Immunizations and parasite challenge}

Groups of 6-to-10-week-old female C57BL/6 a1,3GalT-KO mice ( $n=6$ per group) were immunized i.p. with $20 \mu \mathrm{g} / \mathrm{dose} / \mathrm{mouse}$ of Gala3LN-HSA alone (Gala3LN-HSA), in combination with $10 \mu \mathrm{g} /$ dose/mouse of LMPLA adjuvant (Gala3LN-HSA+LMPLA), or with the carrier protein and adjuvant alone (HSA+LMPLA) as the control group. A naive group was also included and handled like the experimental groups. Three days before prime $(\mathrm{N})$, blood was collected from all groups to obtain baseline serum levels. Immunizations were achieved by one prime $(P)$ and three boost immunizations (B1, B2, and B3), i.p., at 7-day intervals, where LMPLA adjuvant was only administered during $P$ and $B 1$ immunizations for the Gala3LN-HSA+LMPLA and HSA+LMPLA groups. All groups were challenged i.p. with $1 \times 10^{5} \mathrm{CL}$ Brener-luc TCTs 3 weeks after B3. Animals were humanely euthanized at the experimental endpoint (EP), 32 days after parasite challenge. Serum was collected between immunizations and throughout the experiment for further analyses. Weight was closely monitored and mice were examined for signs of toxicity and abnormal behavior. Survival of experiment was recorded up to experimental endpoint.

In vivo whole-body parasite bioluminescence imaging

Mice were analyzed for whole-body parasite burden using IVIS Lumina III In Vivo Imaging System (PerkinElmer, Waltham, MA), as described. ${ }^{40}$ Previous to imaging, mice were injected i.p. with $150 \mathrm{mg} / \mathrm{kg}$ D-luciferin, potassium salt (Gold Biotechnology, St. Louis, MO), in $100 \mu \mathrm{L}$ PBS, and anesthetized soon after with $2 \%$ isofluorene gas with oxygen. Live animal images were acquired in the automatic exposure setting $10 \mathrm{~min}$ after D-luciferin injection.

Anti- $a-G a l ~ A b$ titers and $A b$ isotype determination by CL-ELISA To determine the levels of anti-a-Gal Abs in naive and TCT-infected a1,3GalT-KO and a1,3GalT-WT mice, 96-well CL-ELISA microplates (ThermoFisher Scientific) were immobilized with $5 \mu \mathrm{g} / \mathrm{mL}$ ( $500 \mathrm{ng} /$ well) of Gala3LNBSA (3-atom spacer, NGP0334, Dextra Laboratories, Reading, UK) in $0.2 \mathrm{M}$ carbonate-bicarbonate buffer, pH 9.6 (CB buffer). Wells were blocked with 
1\% BSA in PBS, pH 7.4 (1\% BSA-PBS), for $1 \mathrm{~h}$ at $37^{\circ} \mathrm{C}$. Mouse sera (at 1:100 dilution) in $1 \%$ BSA-PBS was added and incubated at $37^{\circ} \mathrm{C}$ for $1 \mathrm{~h}$. Microplates were then sequentially incubated with $50 \mu \mathrm{L}$ of each goat antimouse IgG ( $1 \mu \mathrm{g} / \mathrm{mL}$; eBioscience, Thermo Fisher Scientific), donkey antigoat lgG-biotin conjugate $(1 \mu \mathrm{g} / \mathrm{mL}$; eBioscience, Thermo Fisher Scientific), and streptavidin-horseradish peroxidase (HRP) $(1: 2000$; Zymed) for $1 \mathrm{~h}$ at $37^{\circ} \mathrm{C}$. Microplates were washed $4 \times$ with $200 \mu \mathrm{L}$ PBS- $0.05 \%$ Tween 20 (PBS$\mathrm{T})$ between incubation steps. For detection of $\mathrm{Ab}$-antigen complexes, the luminescent reagent $(50 \mu \mathrm{L}$, at 1:20 dilution in $C B$ buffer; $E C L$, Pierce, Thermo Fisher Scientific) was added and relative luminescence units were measured using a Luminoskan Ascent luminometer (eBiosystems, Thermo Fisher Scientific).

Anti-a-Gal $A b$ titers in the sera of mice immunized with Gala3LN-H SA+/-LMPLA were determined by CL-ELISA, ${ }^{29}$ as detailed in Methods. First, antigen and serum pools were cross-titrated to optimize the immunoassay. Gala3LN-HSA was immobilized at $125 \mathrm{ng} /$ well in CB buffer. Free binding sites were blocked with $5 \%$ skim milk in PBS), for $1 \mathrm{~h}$ at $37^{\circ} \mathrm{C}$. Mouse sera collected at various timepoints throughout study (Fig. 2) were used as primary Abs at 1:100 dilution in PBS-T), for $1 \mathrm{~h}$ at $37^{\circ} \mathrm{C}$. Donkey anti-mouse IgG biotin-conjugated Ab (1:2000 dilution) was used as secondary $A b$, followed by High Sensitivity NeutrAvidin-HRP enzyme (1:5000 dilution) (both conjugates were from Thermo Fisher Scientific), both for $1 \mathrm{~h}$ at $37^{\circ} \mathrm{C}$. CL-ELISA was developed with SuperSignal ELISA Pico Chemiluminescent Substrate, at 1:8 dilution in CB buffer with $0.1 \%$ BSA to reduce the nonspecific luminescence, ${ }^{90}$ using a Luminoskan luminometer (both from Thermo Fisher Scientific). Microplates were washed $3 \times$ with $200 \mu \mathrm{L}$ PBS-T between incubation steps except before blocking.

$A b$ isotype levels of $\lg G 1, \lg G 2 b, \lg G 3, \lg M, \lg A$, and $\lg E$ specific to Gala3LN-HSA were also analyzed by CL-ELISA using the same protocol and specific isotypes as secondary Abs conjugated to HRP (goat anti-mouse IgG1-HRP, goat anti-mouse IgG2b-HRP, and goat anti-mouse lgG3-HRP, goat anti-mouse IgM-HRP, goat anti-mouse IgA-HRP, and rat anti-mouse IgE-HRP; Abcam, Cambridge, MA).

For $\lg \mathrm{M}, \lg \mathrm{A}$, and $\lg E$ measurement, prior to the CL-ELISA we depleted IgG $A b s$ by preincubating each serum sample with a $15-\mu \mathrm{L}$ bead suspension mixture of protein $A$-Sepharose $4 B$ and protein $G$-Sepharose (A:G, 1:1, v/v), both fast flow (Millipore-Sigma, St. Louis, MO), and recombinant $\mathrm{HSA}(1 \mathrm{mg} / \mathrm{mL})$, for $1 \mathrm{~h}$ at $37^{\circ} \mathrm{C}$ in rotatory shaker.

\section{Quantitative real-time PCR (qPCR) analysis of parasitic load in tissues}

At experimental endpoint, mice were euthanized by $\mathrm{CO}_{2}$ overdose, and several organs were harvested for semiquantitative parasite load quantification. ${ }^{91}$ Briefly, genomic DNA was extracted from $20-30 \mathrm{mg}$ of tissue using the High Pure PCR Template Preparation Kit (Roche Diagnostics, Indianapolis, IN), following the manufacturer's instructions. Before extraction, tissue was homogenized in sterile, ice-cold PBS using sterile gentleMACS $M$ tubes on the gentleMACS dissociator (Miltenyi Biotec, Auburn, $\mathrm{CA}$ ), running in the protein program mode. All samples were spiked with $5 \mu \mathrm{L}$ of a $40 \mathrm{pg} / \mu \mathrm{L}$ of linearized pUC57 plasmid, containing the following sequence (base pairs 434-614) from Arabidopsis thaliana tonoplast intrinsic protein $5 ; 1(\mathrm{TIP} 5 ; 1)$ gene (accession number: NM_114612), as an internal amplification control (IAC) ${ }^{92}: 5^{\prime}$-ACCGTC ATGGAACAGCACGTACCGATTIATAAGATTGCTGGAGAAATGACTGGATTTGG AGCATCTGTTCTTGAAGGTGTITIAGCTTTCGTCTTGGTTIATACTGTGTTCACG GCTAGCGATCCCAGACGTGGGCTACCTITAGCAGTGGGACCTATATTTATAG GGTTTGTTGCGGGAG-3'. After DNA extraction, all samples were diluted to $20 \mathrm{ng} / \mu \mathrm{L}$ and a total of $100 \mathrm{ng}$ of DNA was used for a final volume of $20 \mu \mathrm{L}$. Amplification of $T$. cruzi satellite DNA was done by using the specific primers $^{93,94}$ Cruzi 1 (5'-ASTCGGCTGATCGTTTCGA-3') and Cruzi 2 (5'-AATTCCTCCAAGCAGCGGATA-3'), both at $750 \mathrm{nM}$, and the TaqMan probe Cruzi 3 (6FAM-CACACACTGGACACCAA-MGB-NFQ) at $50 \mathrm{nM}$. Both the forward (5'-ACCGTCATGGAACAGCACGTA- $3^{\prime}$ ) and the reverse (5'-CTCCCGCAACAAACCCTATAAAT-3') primers for the IAC were used at $100 \mathrm{nM}$, and the TaqMan probe (VIC-AGCATCTGTTCTTGAAG GT-MGB-NFQ) was used at $50 \mathrm{nM}$. Standard curves were done with a spiked pool of naive tissue lysate (heart, spleen, colon, stomach, lungs, liver, intestine, and skeletal muscle) with $1 \times 10^{5}$ parasites $/ \mathrm{mL}$ and diluting $1 / 10$ in naive mouse DNA. PCR conditions were as detailed above and consisted of $50^{\circ} \mathrm{C}$ for $2 \mathrm{~min}, 94^{\circ} \mathrm{C}$ for $10 \mathrm{~min}$, followed by 40 cycles at $95^{\circ} \mathrm{C}$ and $58^{\circ} \mathrm{C}$ for $1 \mathrm{~min}$; fluorescence was collected after each cycle. All samples were run in duplicate in Step One Plus Real Time PCR System (Applied Biosystems, Foster City, CA).

\section{a-Galactosidase treatment}

First, MaxiSorp Nunc polystyrene microplate (Thermo Fisher Scientific) wells were coated with $125 \mathrm{ng} /$ well of Gala3LN-HSA in CB buffer and incubated $\mathrm{O} / \mathrm{N}$ at $4^{\circ} \mathrm{C}$. The microplate free sites were blocked with $200 \mu \mathrm{L}$ $5 \%$ skim milk-PBS for $1 \mathrm{~h}$ at $37^{\circ} \mathrm{C}$, washed three times with $150 \mu \mathrm{L}$ PBS-T, and subsequently washed twice with $150 \mu \mathrm{L}$ of $100 \mathrm{mM}$ potassium phosphate buffer ( $\mathrm{pH} 6.5)$, to equilibrate the microplate to the appropriate $\mathrm{pH}$ before enzyme addition. Then green coffee bean a-galactosidase (in ammonium sulfate suspension, $\geq 9$ units/mg protein; G8507, Sigma-Aldrich) was centrifuged at $10,000 \times g$ for $10 \mathrm{~min}$ at $4{ }^{\circ} \mathrm{C}$ to remove excess ammonium sulfate. The supernatant was discarded and the pellet containing the enzyme was gently resuspended in ice-cold $100 \mathrm{mM}$ potassium phosphate buffer $(\mathrm{pH} 6.5)$. Fifty microliters of the enzyme solution ( $0.5 \mathrm{U} /$ well) were added to each well, and the plate was incubated for $24 \mathrm{~h}$ at $37^{\circ} \mathrm{C}$ in a humid chamber. The microplate was washed twice with $200 \mu \mathrm{L}$ PBS-T and CL-ELISA was performed as described above. The reduction of reactivity of specific IgG Abs elicited in mice immunized with Gala3LN-HSA or Gala3LN-HSA+LMPLA was compared against enzymeuntreated wells that were incubated with the $100 \mathrm{mM}$ potassium phosphate buffer under the same conditions.

\section{Parasite lysis assay}

Y strain or CL Brener-luc T. cruzi TCTs $\left(20 \mu \mathrm{L}\right.$ of $1 \times 10^{6}-10^{7}$ parasites $/ \mathrm{mL}$ in DMEM, pH 7.4) were preincubated with 1,10 , or $100 \mu \mathrm{g}$ of purified murine anti-a-Gal Abs, obtained as described above. In parallel, 2 or $20 \mu \mathrm{L}$ of serum from mice immunized with Gala3LN-HSA or Gala3LN-HSA+LMPLA was also incubated in the presence of $100 \mathrm{mM} \mathrm{MgCl}$ (to reduce parasite sialic acid inhibitory effect on anti-a-Gal $\mathrm{Abs}^{22}$ ), for $30-60 \mathrm{~min}$, at $37^{\circ} \mathrm{C}$, under a humidified atmosphere of $5 \% \mathrm{CO}_{2}$. As controls, TCTs in PBS (negative control, live), TCTs preincubated with $4 \%$ formaldehyde (positive control, dead), and NMS (negative control) at the same incubation conditions. Purified human anti-a-Gal Abs from chronic ChD patients (Ch anti-a-Gal Abs, at $20 \mu \mathrm{g} / \mathrm{mL}$ ), obtained as described ${ }^{19}$ and detailed above, was incubated with TCTs in the presence of $100 \mathrm{mM} \mathrm{MgCl}$, under the same conditions. After incubation, samples were loaded onto a hemocytometer (Thermo Fisher Scientific) and both live and dead parasites were counted in triplicate determinations.

Immunoaffinity purification of murine anti-a-Gal antibodies obtained by immunization with Gala3LN-HSA+/-LMPLA

Gala3LN-HSA $(50 \mu \mathrm{g})$ was spotted and air-dried onto nitrocellulose membrane strips (Thermo Fisher Scientific) and incubated for $1 \mathrm{~h}$ at $37^{\circ} \mathrm{C}$ in PBS, under gentle agitation using a rotatory shaker. Membrane was then blocked with $1 \%$ BSA-PBS for $1 \mathrm{~h}$ at $37^{\circ} \mathrm{C}$ on shaker and washed three times with PBS. Then serum pools from mice immunized with Gala3LN-HSA, Gala3LN-HSA+LMPLA, or HSA+LMPLA (control group), or from naive animals, at day -7 , were diluted 1:10 in PBS and added to the blocked nitrocellulose membrane. The membrane was incubated $\mathrm{O} / \mathrm{N}$ at $4{ }^{\circ} \mathrm{C}$ on rotatory shaker, then washed three times with PBS. Bound Abs were eluted with $50 \mathrm{mM}$ citric acid, $\mathrm{pH} 2.8$, and immediately neutralized with $1 \mathrm{M}$ Tris- $\mathrm{HCl}, \mathrm{pH}$ 8.0. Eluates were dialyzed by centrifugation in a $30-$ kDa Amicon Ultra-15 Centrifugal Filter Unit (Millipore Sigma) and washed with PBS. Ab concentration was measured with the Pierce BCA Protein Assay Kit (Thermo Fisher Scientific) and stored at $4{ }^{\circ} \mathrm{C}$ in PBS- $0.1 \%$ sodium azide until use. We obtained 306, 534, 741, and $302 \mu \mathrm{g} / \mathrm{mL}$ of Abs from the Gala3LN-HSA, Gala3LN-HSA+LMPLA, HSA+LMPLA, and naive groups at day -7 , respectively.

\section{Confocal immunofluorescence microscopy}

$\mathrm{CL}$ Brener-luc TCTs from 4-6-day-infected LLC-MK2 cells were collected in DMEM- $0.2 \%$ BSA (no FBS) for $2 \mathrm{~h}$ at $37^{\circ} \mathrm{C}$, at $5 \% \mathrm{CO}_{2}$, to devoid parasites of sialic acid added via TS action. ${ }^{22}$ After incubation, $1 \times 10^{6}$ parasites were air-dried on each well of a Nunc 4-well chambered slide (Thermo Fisher) and immediately fixed with $500 \mu \mathrm{L}$ of ice-cold methanol for $5 \mathrm{~min}$, at $-20^{\circ} \mathrm{C}$. Chambered slides were gently washed three times with $500 \mu \mathrm{L}$ PBS. Parasites were then blocked $\mathrm{O} / \mathrm{N}$ at $4{ }^{\circ} \mathrm{C}$ with $500 \mu \mathrm{L}$ of $2 \%$ BSA in PBS. Parasites were washed three times with $500 \mu \mathrm{L}$ PBS, then purified $\mathrm{Ch}$ anti- $a-G a l$ and murine $C h$ anti-a-Gal lgG Abs were added at $1 \mu \mathrm{g} / \mathrm{mL}$ in $500 \mu \mathrm{L} 0.1 \% \mathrm{BSA}$, and incubated $\mathrm{O} / \mathrm{N}$ at $4{ }^{\circ} \mathrm{C}$. Parasites were washed three times with $500 \mu \mathrm{L}$ PBS, then incubated with goat anti-mouse $\operatorname{lgG}(\mathrm{H}+\mathrm{L})$ Highly Cross-Adsorbed Secondary Ab Alexa Fluor ${ }^{\mathrm{TM}} 594$ and isolectin GS-IB from Griffonia simplicifolia labeled with Alexa Fluor ${ }^{\mathrm{TM}} 488$ (both from 
Thermo Fisher Scientific), at $5 \mu \mathrm{g} / \mathrm{mL}$, for $1 \mathrm{~h}$ at RT, protected from light. Finally, parasites were washed three times with $500 \mu \mathrm{L}$ PBS and chambers were removed from slides, allowed to air-dry, mounted with a drop of Vectashield antifade mounting medium (Vector Laboratories, Burlingame, (A), and coverslips were sealed with nail polish. Images were captured using a Zeiss LSM 700 confocal microscope equipped with $\times 63$ oil immersion objective; images were acquired using 1-Airy unit and 1024-by1024-pixel resolution. Zen 2009 software was used to capture and analyze images (Zeiss, Oberkochen, Germany).

\section{Analysis of serum cytokines}

For comparing the serum cytokine profile of a1,3GalT-KO versus a1,3GalTWT mice infected with TCTs, serum was collected from both groups in a period of 4 weeks of infection. Cytokine measurements (IFN- $\gamma$, TNF- $a$, IL-2, IL-4, and IL-10) were performed by sandwich ELISA and compared to commercial standard curve according to the manufacturer (BD Biosciences, Franklin Lakes, NJ). Vaccinated mouse serum cytokines and chemokines (Eotaxin (or CCL11), G-CSF, GM-CSF, IFN- $\gamma$, IL-1a, IL-1 $\beta$, IL-2, IL-3, IL-4, IL-5, IL-6, IL-7, IL-9, IL-10, IL-12 (p40), IL-12 (p70), IL-13, IL-15, IL-17, IP-10 (or CXCL10), KC-like (or CXCL1), LIF, LIX (or CXCL5), MCP-1 (or CCL2), M-CSF, MIG (or CXCL9), MIP-1a (or CCL3), MIP-1 $\beta$ (or CCL4), MIP-2 (or CXCL2), RANTES (or CCL5), TNF- $a$, and VEGF) were analyzed using the MILLIPLEX MAP Mouse Cytokine/Chemokine Magnetic Bead Panel Premixed 32 Plex using the manufacturer's protocol (EMD Millipore, Billerica, MA). Briefly, sera obtained from experimental endpoint (32 dpi) were diluted 1:2 and subjected to analysis by fold change against the challenged-only group. Results are representative of two biological replicates, and all determinations were performed in duplicate.

\section{$\mathrm{CD}^{+}$and $\mathrm{CD}^{+}{ }^{+} \mathrm{T}$ cell analysis by flow cytometry}

Splenocytes were harvested from a1,3GalT-KO mice after immunizations and at experimental endpoint (Fig. 2a) in $10 \mathrm{~mL}$ of ACK red blood cell lysis buffer $(0.83 \%$ ammonium chloride, $0.1 \%$ potassium bicarbonate, $0.04 \%$ EDTA, pH 7.4) and washed in freshly prepared complete DMEM (DMEM $+10 \%$ heat-inactivated FBS $+1 \%$ penicillin-streptomycin) with addition of $50 \mu \mathrm{M}$ 2-mercaptoethanol. Cells were seeded in 12-well flatbottom plates (Corning, Thermo Fisher Scientific) and stimulated with $20 \mu \mathrm{g} / \mathrm{mL}$ Gala3LN-HSA and incubated for $24 \mathrm{~h}$ at $37^{\circ} \mathrm{C}$, with $5 \% \mathrm{CO}_{2}$. After incubation, supernatant was removed and cells were washed with sterile PBS containing $1 \%$ BSA and $0.09 \%$ sodium azide (PBSA/Az). The FcyR was blocked with $10 \%$ fresh mouse serum in PBS and incubated on ice for $15 \mathrm{~min}$. After a PBSA/Az wash, cells were resuspended in complete DMEM and cells were stained with fluorochrome-conjugated Abs PECy7-labeled anti-CD3e, PE-labeled anti-CD4, FITC-labeled anti-CD8, and APC-labeled anti-CD44 (all conjugates from BD Bioscience, San Jose, CA and Tonbo Biosciences, San Diego, CA) for 30 min at $4{ }^{\circ} \mathrm{C}$, protected from light. After another wash with $\mathrm{PBS} / \mathrm{Az}$, cells were fixed with $1 \%$ paraformaldehyde and transferred to FACS tubes. A total of 50,000 events were analyzed by flow cytometry using the Gallios Flow Cytometer and analyzed with the Kaluza Analysis Software (Beckman Coulter, Brea, CA). Gates were set for lymphocyte cells (CD3e-PE-Cy7 labeling) using forward and side scatter properties, and the percentages of activated $\mathrm{CD}^{+}{ }^{+}$and $\mathrm{CD} 8^{+} \mathrm{T}$ cells were obtained on gated $\mathrm{CD}^{+} \mathrm{T}$ cells (Supplementary Figure 3).

\section{Histopathology}

Hearts from animals immunized with Gala3LN-HSA or Gala3LN-HSA+LMPLA and from the control groups (HSA+LMPLA and naive) were harvested and immediately cut longitudinally and fixed in $4 \%$ paraformaldehyde (Thermo Fisher Scientific), $\mathrm{O} / \mathrm{N}$ at $4{ }^{\circ} \mathrm{C}$. Then tissue sections were sequentially incubated in $15 \%$ and $30 \%$ sucrose in PBS, for $48 \mathrm{~h}$ at $4^{\circ} \mathrm{C}$. Samples were then embedded in paraffin, sectioned, stained with hematoxylin and eosin, and analyzed at MD Anderson Cancer Center (MDACC) Science Park Research Histology, Pathology \& Imaging Core (Smithville, TX). In each section of the heart, the infiltration of mononuclear cells in the left ventricle from 25 fields (at $\times 400$ ) was manually counted and analyzed. Moreover, heart sections were stained for $\mathrm{CD}^{+} \mathrm{T}$ cells with rat anti-human $\mathrm{CD} 3 \mathrm{mAb}$ (clone CD3-12, Serotec/Bio-Rad), which cross-reacts with mouse CD3; for $\mathrm{CD}^{+}{ }^{+} \mathrm{T}$ cell with rat anti-mouse CD4 mAb (clone 4SM95, eBioscience, Invitrogen); and for CD8 ${ }^{+} \mathrm{T}$ cell with rat anti-mouse CD8 mAb (clone 4SM15, eBioscience, Invitrogen). Images were acquired using an Aperio ScanScope CS Digital Pathology Scanner (Leica Biosystems, Buffalo Grove, IL).
Statistical analysis

Data points are presented as the average of triplicate determinations with their corresponding standard error of the means (S.E.M.). Kaplan-Meier survival rate curves, Student's $t$ test, one-way analysis of variance (ANOVA), or two-way ANOVA were employed in the statistical analysis, as indicated in the figure legends. Graphs and statistical analysis were achieved using the Graph Pad Prism 7 Software (GraphPad Software, Inc., La Jolla, CA).

\section{Reporting summary}

Further information on research design is available in the Nature Research Reporting Summary linked to this article.

\section{DATA AVAILABILITY}

All data that support the findings of this study are available from the corresponding author upon reasonable request.

\section{ACKNOWLEDGEMENTS}

We are grateful to Professor Luiz R. Travassos (Universidade Federal de São PauloUNIFESP, Brazil) and Dr. Alvaro Acosta-Serrano (Liverpool School of Tropical Medicine, UK) for the critical reading of the manuscript, insightful comments, and continuous support. We are also grateful to Dr. Joaquim Gascón (ISGlobal, Barcelona) for kindly donating the serum samples from adult chronic ChD patients; to Professor Peter J. Cowan, St. Vincent's Hospital Melbourne and University of Melbourne for kindly donating the a1,3GalT-KO mice; to Dr. Charles T. Spencer (UTEP) for thoughtful comments and helpful discussions; and Luiz S. Silva (UNIFESP, Brazil) and Maria V.D. Guadalupe (UTEP) for technical assistance. We thank the UTEP/BBRC Core Facilities: Biomolecule Analysis (BACF), Cytometry, Screening and Imaging (CSI), and Genomic Analysis (GACF). All three BBRC/UTEP Core Facilities are supported by a grant (2G12MD007592) from the National Institute on Minority Health and Health Disparities (NIMHD). This study made use of the Research Histology, Pathology, and Imaging Core, supported by P30 CA16672 DHHS/NCl Cancer Center Support Grant (CCSG). This project was funded by NIH grant 1R21Al115451 (to I.C.A. and K.M.) and partially funded by UTEP College of Science Multidisciplinary Pilot Projects and Collaborations Grant (to I.C.A. and K.M.). S.P. was recipient of Dr. Keelung Hong Graduate Research Fellowship and UTEP Dodson Research Grant. E.I. was recipient of the Diana Natalicio Doctoral Dissertation Fellowship and RISE Scholars Program at UTEP (NIGMS grant \#R25GM069621-11). N.K.H. was recipient of Frank B. Cotton Trust Scholarship, from UTEP Graduate School. J.J.O. is fellow of the BUILDing Scholars Program at UTEP.

\section{AUTHOR CONTRIBUTIONS}

S.P., B.G.Z., E.I., J.J.O., N.K.H., and A.F.M. conducted the experiments and analyzed data. O. C.M. designed experiments and analyzed data. K.M. and R.A.M. assisted in experimental design and data analysis. I.C.A. designed experiments, analyzed data, and coordinated all experiments. S.P., E.I., A.F.M., and I.C.A. wrote the manuscript. All the authors participated in revising the manuscript and have approved the final version.

\section{ADDITIONAL INFORMATION}

Supplementary information accompanies the paper on the npj Vaccines website (https://doi.org/10.1038/s41541-019-0107-7).

Competing interests: The authors declare no competing interests.

Publisher's note: Springer Nature remains neutral with regard to jurisdictional claims in published maps and institutional affiliations.

\section{REFERENCES}

1. Bern, C. Chagas' disease. N. Engl. J. Med. 373, 456-466 (2015).

2. Rassi, A. Jr, Rassi, A. \& Marin-Neto, J. A. Chagas disease. Lancet 375, 1388-1402 (2010).

3. Urbina, J. A. Recent clinical trials for the etiological treatment of chronic chagas disease: advances, challenges and perspectives. J. Eukaryot. Microbiol. 62, 149-156 (2015)

4. Ribeiro, I. et al. New, improved treatments for Chagas disease: from the R\&D pipeline to the patients. PLoS Negl. Trop. Dis. 3, e484 (2009).

5. Beaumier, C. M. et al. Status of vaccine research and development of vaccines for Chagas disease. Vaccine 34, 2996-3000 (2016). 
6. Quijano-Hernandez, I. \& Dumonteil, E. Advances and challenges towards a vaccine against Chagas disease. Hum. Vaccin. 7, 1184-1191 (2011).

7. Cuervo, P., Domont, G. B. \& De Jesus, J. B. Proteomics of trypanosomatids of human medical importance. J. Proteom. 73, 845-867 (2010).

8. Menna-Barreto, R. F. \& Perales, J. The expected outcome of the Trypanosoma cruzi proteomic map: a review of its potential biological applications for drug target discovery. Subcell. Biochem. 74, 305-322 (2014).

9. Zingales, B. et al. The revised Trypanosoma cruzi subspecific nomenclature: rationale, epidemiological relevance and research applications. Infect. Genet. Evol. 12, 240-253 (2012).

10. Acosta-Serrano, A., Hutchinson, C., Nakayasu, E. S., Almeida, I. C. \& Carrington, M. In Trypanosomes: After the Genome (eds. Barry, J. D., Mottram, J. C., McCulloch, R. \& Acosta-Serrano, A.) 319-337 (Horizon Scientific Press, Poole, 2007).

11. Pereira, I. R. et al. A human type 5 adenovirus-based Trypanosoma cruzi therapeutic vaccine re-programs immune response and reverses chronic cardiomyopathy. PLoS Pathog. 11, e1004594 (2015).

12. Dos Santos Virgilio, F. et al. CD8(+) T cell-mediated immunity during Trypanosoma cruzi infection: a path for vaccine development? Mediat. Inflamm. 2014, 243786 (2014)

13. Sanchez Alberti, A. et al. Engineered trivalent immunogen adjuvanted with a STING agonist confers protection against Trypanosoma cruzi infection. npj Vaccines 2, 9 (2017)

14. Villanueva-Lizama, L. E. et al. Trypanosoma cruzi vaccine candidate antigens Tc24 and TSA-1 recall memory immune response associated with HLA-A and -B supertypes in Chagasic chronic patients from Mexico. PLoS Negl. Trop. Dis. 12, e0006240 (2018).

15. Almeida, I. C., Ferguson, M. A., Schenkman, S. \& Travassos, L. R. Lytic anti-alphagalactosyl antibodies from patients with chronic Chagas' disease recognize novel O-linked oligosaccharides on mucin-like glycosyl-phosphatidylinositol-anchored glycoproteins of Trypanosoma cruzi. Biochem. J. 304, 793-802 (1994).

16. Buscaglia, C. A. et al. The surface coat of the mammal-dwelling infective trypomastigote stage of Trypanosoma cruzi is formed by highly diverse immunogenic mucins. J. Biol. Chem. 279, 15860-15869 (2004).

17. Milani, S. R. \& Travassos, L. R. Anti-alpha-galactosyl antibodies in chagasic patients. Possible biological significance. Braz. J. Med. Biol. Res 21, 1275-1286 (1988).

18. Avila, J. L., Rojas, M. \& Galili, U. Immunogenic Gal alpha 1-3Gal carbohydrate epitopes are present on pathogenic American Trypanosoma and Leishmania. J. Immunol. 142, 2828-2834 (1989).

19. Almeida, I. C., Milani, S. R., Gorin, P. A. \& Travassos, L. R. Complement-mediated lysis of Trypanosoma cruzi trypomastigotes by human anti-alpha-galactosyl antibodies. J. Immunol. 146, 2394-2400 (1991).

20. Gazzinelli, R. T., Pereira, M. E., Romanha, A., Gazzinelli, G. \& Brener, Z. Direct lysis of Trypanosoma cruzi: a novel effector mechanism of protection mediated by human anti-gal antibodies. Parasite Immunol. 13, 345-356 (1991).

21. Almeida, I. C., Krautz, G. M., Krettli, A. U. \& Travassos, L. R. Glycoconjugates of Trypanosoma cruzi: a $74 \mathrm{kD}$ antigen of trypomastigotes specifically reacts with lytic anti-alpha-galactosyl antibodies from patients with chronic Chagas disease. J. Clin. Lab. Anal. 7, 307-316 (1993).

22. Pereira-Chioccola, V. L. et al. Mucin-like molecules form a negatively charged coat that protects Trypanosoma cruzi trypomastigotes from killing by human antialpha-galactosyl antibodies. J. Cell Sci. 113, 1299-1307 (2000).

23. de Andrade, A. L. et al. Randomised trial of efficacy of benznidazole in treatment of early Trypanosoma cruzi infection. Lancet 348, 1407-1413 (1996).

24. Torrico, F. et al. Treatment of adult chronic indeterminate Chagas disease with benznidazole and three E1224 dosing regimens: a proof-of-concept, randomised, placebo-controlled trial. Lancet Infect. Dis. 18, 419-430 (2018).

25. Galili, U., Wang, L., LaTemple, D. C. \& Radic, M. Z. In a-Gal and Anti-Gal. Subcellular Biochemistry, Vol. 32 (eds. Galili, U. \& Avila, J.L.) 79-106 (Springer, New York, 1999).

26. Galili, U. In The Natural Anti-Gal Antibody as Foe Turned Friend in Medicine Ch. 1 (Elsevier - Academic Press, London, 2017).

27. Wilkinson, S. G. Bacterial lipopolysaccharides-themes and variations. Prog. Lipid Res. 35, 283-343 (1996).

28. Schocker, N. S. et al. In Coupling and Decoupling of Diverse Molecular Units in Glycosciences (eds. Witzczak, Z. J. \& Bielski, R.) 195-211 (Springer International Publishing AG, Basel, 2018).

29. Schocker, N. S. et al. Synthesis of Galalpha(1,3)Galbeta(1,4)GlcNAcalpha-, Galbeta $(1,4)$ GlcNAcalpha- and GlcNAc-containing neoglycoproteins and their immunological evaluation in the context of Chagas disease. Glycobiology 26, 39-50 (2016).

30. Macher, B. A. \& Galili, U. The Galalpha1,3Galbeta1,4GIcNAc-R (alpha-Gal) epitope: a carbohydrate of unique evolution and clinical relevance. Biochim. Biophys. Acta 1780, 75-88 (2008).

31. Cabezas-Cruz, A. \& de la Fuente, J. Immunity to alpha-Gal: toward a singleantigen pan-vaccine to control major infectious diseases. ACS Cent. Sci. 3, 1140-1142 (2017)
32. Yilmaz, B. et al. Gut microbiota elicits a protective immune response against malaria transmission. Cell 159, 1277-1289 (2014).

33. Iniguez, E. et al. An alpha-Gal-containing neoglycoprotein-based vaccine partially protects against murine cutaneous leishmaniasis caused by Leishmania major. PLoS Negl. Trop. Dis. 11, e0006039 (2017).

34. Moura, A. P. V. et al. Virus-like particle display of the alpha-Gal carbohydrate for vaccination against Leishmania infection. ACS Cent. Sci. 3, 1026-1031 (2017).

35. Thall, A. D., Murphy, H. S. \& Lowe, J. B. alpha 1,3-Galactosyltransferase-deficient mice produce naturally occurring cytotoxic anti-Gal antibodies. Transplant. Proc. 28, 556-557 (1996).

36. Tearle, R. G. et al. The alpha-1,3-galactosyltransferase knockout mouse. Implications for xenotransplantation. Transplantation 61, 13-19 (1996).

37. Galili, U. \& Swanson, K. Gene sequences suggest inactivation of alpha-1,3galactosyltransferase in catarrhines after the divergence of apes from monkeys. Proc. Natl Acad. Sci. USA 88, 7401-7404 (1991).

38. Almeida, I. C., Ferguson, M. A., Schenkman, S. \& Travassos, L. R. GPI-anchored glycoconjugates from Trypanosoma cruzi trypomastigotes are recognized by lytic anti-alpha-galactosyl antibodies isolated from patients with chronic Chagas' disease. Braz. J. Med. Biol. Res. 27, 443-447 (1994).

39. Thall, A. D., Maly, P. \& Lowe, J. B. Oocyte Gal alpha 1,3Gal epitopes implicated in sperm adhesion to the zona pellucida glycoprotein ZP3 are not required for fertilization in the mouse. J. Biol. Chem. 270, 21437-21440 (1995).

40. Lewis, M. D. et al. Bioluminescence imaging of chronic Trypanosoma cruzi infections reveals tissue-specific parasite dynamics and heart disease in the absence of locally persistent infection. Cell Microbiol. 16, 1285-1300 (2014).

41. Wood, C., Kabat, E. A., Murphy, L. A. \& Goldstein, I. J. Immunochemical studies of the combining sites of the two isolectins, A4 and B4, isolated from Bandeiraea simplicifolia. Arch. Biochem. Biophys. 198, 1-11 (1979).

42. Machado, F. S. et al. Current understanding of immunity to Trypanosoma cruzi infection and pathogenesis of Chagas disease. Semin. Immunopathol. 34, 753-770 (2012).

43. Gascon, J., Bern, C. \& Pinazo, M. J. Chagas disease in Spain, the United States and other non-endemic countries. Acta Trop. 115, 22-27 (2010).

44. Bern, C., Kjos, S., Yabsley, M. J. \& Montgomery, S. P. Trypanosoma cruzi and Chagas' disease in the United States. Clin. Microbiol. Rev. 24, 655-681 (2011).

45. Horstick, O. \& Runge-Ranzinger, S. Protection of the house against Chagas disease, dengue, leishmaniasis, and lymphatic filariasis: a systematic review. Lancet Infect. Dis. 18, e147-e158 (2018).

46. Balouz, V., Aguero, F. \& Buscaglia, C. A. Chagas disease diagnostic applications: present knowledge and future steps. Adv. Parasitol. 97, 1-45 (2017).

47. Alonso-Padilla, J., Gallego, M., Schijman, A. G. \& Gascon, J. Molecular diagnostics for Chagas disease: up to date and novel methodologies. Expert. Rev. Mol. Diagn. 17, 699-710 (2017).

48. Chagas disease in Latin America: an epidemiological update based on 2010 estimates. Wkly. Epidemiol. Rec. 90, 33-43 (2015).

49. Requena-Mendez, A. et al. Prevalence of Chagas disease in Latin-American migrants living in Europe: a systematic review and meta-analysis. PLoS Negl. Trop. Dis. 9, e0003540 (2015).

50. Arce-Fonseca, M., Rios-Castro, M., Carrillo-Sanchez Sdel, C., Martinez-Cruz, M. \& Rodriguez-Morales, O. Prophylactic and therapeutic DNA vaccines against Chagas disease. Parasit. Vectors 8, 121 (2015).

51. dos Santos, S. L. et al. The MASP family of Trypanosoma cruzi: changes in gene expression and antigenic profile during the acute phase of experimental infection. PLoS Negl. Trop. Dis. 6, e1779 (2012).

52. Reis-Cunha, J. L., Valdivia, H. O. \& Bartholomeu, D. C. Gene and chromosomal copy number variations as an adaptive mechanism towards a parasitic lifestyle in trypanosomatids. Curr. Genom. 19, 87-97 (2018).

53. El-Sayed, N. M. et al. The genome sequence of Trypanosoma cruzi, etiologic agent of Chagas disease. Science 309, 409-415 (2005).

54. Belew, A. T. et al. Comparative transcriptome profiling of virulent and nonvirulent Trypanosoma cruzi underlines the role of surface proteins during infection. PLoS Pathog. 13, e1006767 (2017).

55. Ashmus, R. A. et al. Potential use of synthetic alpha-galactosyl-containing glycotopes of the parasite Trypanosoma cruzi as diagnostic antigens for Chagas disease. Org. Biomol. Chem. 11, 5579-5583 (2013).

56. Campo, V. L., Marchiori, M. F. \& Carvalho, I. Insights into anti-trypanosomal agents based on synthetic glycoconjugates. Curr. Top. Med Chem. 18, 382-396 (2018).

57. Avila, J. L. alpha-Galactosyl-bearing epitopes as potent immunogens in Chagas' disease and leishmaniasis. Subcell. Biochem. 32, 173-213 (1999).

58. Galili, U., Wigglesworth, K. \& Abdel-Motal, U. M. Intratumoral injection of alphagal glycolipids induces xenograft-like destruction and conversion of lesions into endogenous vaccines. J. Immunol. 178, 4676-4687 (2007).

59. Abdel-Motal, U. M., Wigglesworth, K. \& Galili, U. Mechanism for increased immunogenicity of vaccines that form in vivo immune complexes with the natural anti-Gal antibody. Vaccine 27, 3072-3082 (2009). 
60. Wigglesworth, K. M. et al. Rapid recruitment and activation of macrophages by anti-Gal/alpha-Gal liposome interaction accelerates wound healing. J. Immunol. 186, 4422-4432 (2011)

61. Travassos, L. R. \& Almeida, I. C. Carbohydrate immunity in American trypanosomiasis. Springer Semin. Immunopathol. 15, 183-204 (1993).

62. Melo, R. C. \& Brener, Z. Tissue tropism of different Trypanosoma cruzi strains. J. Parasitol. 64, 475-482 (1978).

63. Pyrrho, A. S., Moraes, J. L., Pecanha, L. M. \& Gattass, C. R. Trypanosoma cruzi: IgG1 and $\lg \mathrm{G} 2 \mathrm{~b}$ are the main immunoglobulins produced by vaccinated mice. Parasitol. Res. 84, 333-337 (1998).

64. Bhatia, V. \& Garg, N. J. Previously unrecognized vaccine candidates control Trypanosoma cruzi infection and immunopathology in mice. Clin. Vaccin. Immunol. 15, 1158-1164 (2008).

65. Matyas, G. R., Muderhwa, J. M. \& Alving, C. R. Oil-in-water liposomal emulsions for vaccine delivery. Methods Enzymol. 373, 34-50 (2003).

66. Casella, C. R. \& Mitchell, T. C. Putting endotoxin to work for us: monophosphoryl lipid A as a safe and effective vaccine adjuvant. Cell. Mol. Life Sci. 65, 3231-3240 (2008).

67. Martinez-Campos, V. et al. Expression, purification, immunogenicity, and protective efficacy of a recombinant Tc24 antigen as a vaccine against Trypanosoma cruzi infection in mice. Vaccine 33, 4505-4512 (2015).

68. Morgado, M. G., Cam, P., Gris-Liebe, C., Cazenave, P. A. \& Jouvin-Marche, E. Further evidence that $\mathrm{BALB} / \mathrm{C}$ and $\mathrm{C} 5 \mathrm{BL} / 6$ gamma $2 \mathrm{a}$ genes originate from two distinct isotypes. $E M B O$ J. 8, 3245-3251 (1989)

69. LaTemple, D. C. \& Galili, U. Adult and neonatal anti-Gal response in knock-out mice foralpha1,3galactosyltransferase. Xenotransplantation 5, 191-196 (1998).

70. Steinke, J. W., Platts-Mills, T. A. \& Commins, S. P. The alpha-gal story: lessons learned from connecting the dots. J. Allergy Clin. Immunol. 135, 589-596 (2015). quiz 597.

71. Chung, C. H. et al. Cetuximab-induced anaphylaxis and IgE specific for galactosealpha-1,3-galactose. N. Engl. J. Med. 358, 1109-1117 (2008)

72. Lantos, A. B. et al. Sialic acid glycobiology unveils Trypanosoma cruzi trypomastigote membrane physiology. PLoS Pathog. 12, e1005559 (2016).

73. Talvani, A. et al. Kinetics of cytokine gene expression in experimental chagasic cardiomyopathy: tissue parasitism and endogenous IFN-gamma as important determinants of chemokine mRNA expression during infection with Trypanosoma cruzi. Microbes Infect. 2, 851-866 (2000).

74. Eickhoff, C. S. et al. Co-administration of a plasmid DNA encoding IL-15 improves long-term protection of a genetic vaccine against Trypanosoma cruzi. PLoS Negl. Trop. Dis. 5, e983 (2011).

75. Osborne, L. C. \& Abraham, N. Regulation of memory T cells by gammac cytokines. Cytokine 50, 105-113 (2010).

76. Aliberti, J. C. et al. Beta-Chemokines enhance parasite uptake and promote nitric oxide-dependent microbiostatic activity in murine inflammatory macrophages infected with Trypanosoma cruzi. Infect. Immun. 67, 4819-4826 (1999).

77. Lal, N., Puri, K. \& Rodrigues, B. Vascular endothelial growth factor B and its signaling. Front. Cardiovasc. Med. 5, 39 (2018).

78. Goswami, R. \& Kaplan, M. H. A brief history of IL-9. J. Immunol. 186, 3283-3288 (2011).

79. Alving, C. R., Peachman, K. K., Rao, M. \& Reed, S. G. Adjuvants for human vaccines. Curr. Opin. Immunol. 24, 310-315 (2012).
80. Tarleton, R. L., Grusby, M. J., Postan, M. \& Glimcher, L. H. Trypanosoma cruzi infection in MHC-deficient mice: further evidence for the role of both class I- and class IIrestricted T cells in immune resistance and disease. Int. Immunol. 8, 13-22 (1996).

81. Rottenberg, M. E. et al. Outcome of infection with different strains of Trypanosoma cruzi in mice lacking CD4 and/or CD8. Immunol. Lett. 45, 53-60 (1995).

82. Tarleton, R. L. The role of T cells in Trypanosoma cruzi infections. Parasitol. Today 11, 7-9 (1995)

83. Hoft, D. F., Schnapp, A. R., Eickhoff, C. S. \& Roodman, S. T. Involvement of CD4(+) Th1 cells in systemic immunity protective against primary and secondary challenges with Trypanosoma cruzi. Infect. Immun. 68, 197-204 (2000).

84. Elgueta, R., de Vries, V. C. \& Noelle, R. J. The immortality of humoral immunity. Immunol. Rev. 236, 139-150 (2010).

85. Avci, F. Y. \& Kasper, D. L. How bacterial carbohydrates influence the adaptive immune system. Annu. Rev. Immunol. 28, 107-130 (2010).

86. Bonney, K. M. \& Engman, D. M. Autoimmune pathogenesis of Chagas heart disease: looking back, looking ahead. Am. J. Pathol. 185, 1537-1547 (2015).

87. Silva, L. H. P. \& Nussenzweig, V. Sobre uma cepa de Trypanosoma cruzi altamente virulenta para o camundongo branco. Folia Clin. Biol. 20, 191-207 (1953).

88. Zingales, B. et al. Trypanosoma cruzi genome project: biological characteristics and molecular typing of clone CL Brener. Acta Trop. 68, 159-173 (1997).

89. Zingales, B. et al. Biological parameters and molecular markers of clone CL Brener -the reference organism of the Trypanosoma cruzi genome project. Mem Inst Oswaldo Cruz 92, 811-814 (1997).

90. Almeida, I. C., Covas, D. T., Soussumi, L. M. \& Travassos, L. R. A highly sensitive and specific chemiluminescent enzyme-linked immunosorbent assay for diagnosis of active Trypanosoma cruzi infection. Transfusion 37, 850-857 (1997).

91. Ramirez, J. C. et al. Analytical validation of quantitative real-time PCR methods for quantification of Trypanosoma cruzi DNA in blood samples from Chagas disease patients. J. Mol. Diagn. 17, 605-615 (2015).

92. Duffy, T. et al. Accurate real-time PCR strategy for monitoring bloodstream parasitic loads in Chagas disease patients. PLoS Negl. Trop. Dis. 3, e419 (2009).

93. Duffy, T. et al. Analytical performance of a multiplex real-time PCR assay using TaqMan probes for quantification of Trypanosoma cruzi satellite DNA in blood samples. PLoS Negl. Trop. Dis. 7, e2000 (2013).

94. Piron, M. et al. Development of a real-time PCR assay for Trypanosoma cruzi detection in blood samples. Acta Trop. 103, 195-200 (2007).

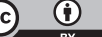

Open Access This article is licensed under a Creative Commons Attribution 4.0 International License, which permits use, sharing, adaptation, distribution and reproduction in any medium or format, as long as you give appropriate credit to the original author(s) and the source, provide a link to the Creative Commons license, and indicate if changes were made. The images or other third party material in this article are included in the article's Creative Commons license, unless indicated otherwise in a credit line to the material. If material is not included in the article's Creative Commons license and your intended use is not permitted by statutory regulation or exceeds the permitted use, you will need to obtain permission directly from the copyright holder. To view a copy of this license, visit http://creativecommons. org/licenses/by/4.0/.

(c) The Author(s) 2019 